\title{
A focused fragment library targeting the antibiotic resistance enzyme - oxacillinase-48: synthesis, structural evaluation and inhibitor design
}

\author{
Sundus Akhter ${ }^{1, \#}$,Bjarte Aarmo Lund ${ }^{2, \#}$, Aya Ismael ${ }^{1}$, Manuel Langer ${ }^{1}$, Johan Isaksson ${ }^{1}$, Tony \\ Christopeit ${ }^{2}$, Hanna-Kirsti S. Leiros ${ }^{2, *}$, Annette Bayer ${ }^{1, *}$ \\ ${ }^{1}$ Department of Chemistry, Faculty of Science and Technology, UiT The Arctic University of Norway, \\ N-9037 Troms $\varnothing$, Norway. ${ }^{2}$ The Norwegian Structural Biology Centre (NorStruct), Department of \\ Chemistry, Faculty of Science and Technology, UiT The Arctic University of Norway, N-9037 Troms $\varnothing$, \\ Norway. \\ * Corresponding authors: Annette Bayer, E-mail: annette.bayer@uit.no ,Phone +47776440 69; \\ Hanna-Kirsti S. Leiros, E-mail: hanna-kirsti.leiros@uit.no ,Phone +47 776457 06; \\ \# These authors have contributed equally to this work. \\ Highlights: \\ - $\quad$ a focused fragment library was employed to explore the binding site of oxacillinase-48 \\ - 33 fragment-enzyme complexes were structurally analyzed \\ - fragment-enzyme interactions useful for future drug design were identified \\ - $\quad$ merged inhibitors with $\mathrm{IC}_{50}$ of $2.9 \mu \mathrm{M}$ were designed by overly of fragments-enzyme structures \\ and structurally analyzed \\ - $\quad$ a synthetic method for unsymmetrically 3,5-disubstituted benzoic acids was developed
}

Keywords: Crystal structure, inhibition properties, benzoic acid derivatives, serine- $\beta$-lactamase inhibitors, fragments, structure-guided drug design.

Abbreviations: DMSO, dimethyl sulfoxide; OXA, oxacillinase; $I C_{50}$, half maximal inhibitory concentration; LE, ligand efficiency; MBL, metallo- $\beta$-lactamase; NMR, nuclear magnetic resonance; $\mathrm{SBL}$, serine- $\beta$-lactamase; SPR, surface plasmon resonance.

Author contributions: Designed the experiments: $A B, B A L, H K S L, S A, T C$. Performed the organic synthesis: $S A, A I, M L$. Determined $I C_{50}$ values and $K_{d}$-values: BAL. Prepared and solved crystal structures: BAL. Analyzed 3D structures: AB, BAL, SA. NMR studies: BAL, JI. Analyzed data and wrote the paper: $A B, B A L, H K S L, J I, S A, T C$. All authors have given approval to the final version of the manuscript. 
Abstract

$\beta$-Lactam antibiotics are of utmost importance when treating bacterial infections in the medical community. However, currently their utility is threatened by the emergence and spread of $\beta$-lactam resistance. The most prevalent resistance mechanism to $\beta$-lactam antibiotics is expression of $\beta$-lactamase enzymes. One way to overcome resistance caused by $\beta$-lactamases, is the development of $\beta$-lactamase inhibitors and today several $\beta$-lactamase inhibitors e.g. avibactam are approved in the clinic. Our focus is the oxacillinase-48 (OXA-48), an enzyme reported to spread rapidly across the world and commonly identified in Escherichia coli and Klebsiella pneumoniae. To guide inhibitor design, we used diversely substituted 3-aryl and 3-heteroaryl benzoic acids to probe the active site of OXA-48 for useful enzyme-inhibitor interactions. In the presented study, a focused fragment library containing 49 3-substituted benzoic acid derivatives were synthesised and biochemically characterized. Based on crystallographic data from 33 fragment-enzyme complexes, the fragments could be classified into $R^{1}$ or $R^{2}$ binders by their overall binding conformation in relation to the binding of the $R^{1}$ and $R^{2}$ side groups of imipenem. Moreover, binding interactions attractive for future inhibitor design were found and their usefulness explored by the rational design and evaluation of merged inhibitors from orthogonally binding fragments. The best inhibitors among the resulting 3,5-disubstituted benzoic acids showed inhibitory potential in the low micromolar range $\left(I C_{50}=2.9 \mu \mathrm{M}\right)$. For these inhibitors, the complex X-ray structures revealed non-covalent binding to Arg250, Arg214 and Tyr211 in the active site and the interactions observed with the mono-substituted fragments were also identified in the merged structures.

\section{Introduction}

Years of overuse of antibiotics have selected for antibiotic resistant strains (1), and today medical personnel are frequently forced to administer last-resort antibiotics. However, the number of cases where last-resort antibiotics fail in treatment are increasing (2) and deaths due to antibiotic resistant infections are expected to surpass cancer deaths by 2050 (3). Bacterial resistance towards clinically important $\beta$-lactam antibiotics (4) like penicillins, cephalosporins and carbapenems originates most often from the occurrence of $\beta$-lactamhydrolysing enzymes - the $\beta$-lactamases.

The $\beta$-lactamase enzymes are of ancient origin (5) and today over 2600 enzymes spanning four classes of $\beta$-lactamases are known (6-8). $\beta$-Lactamases are grouped into two super families based on the enzyme mechanism for $\beta$-lactam hydrolysis: the serine dependent $\beta$ lactamases (SBLs; Amber class A, C, and D) and metallo- $\beta$-lactamases (MBLs; Amber class B) $(7,9)$. SBLs are characterized by a serine residue in the active site, while MBLs require a metal co-factor, usually one or two zinc ions, for enzyme activity. This work focuses on the class $D$ SBLs - also called oxacillinases (OXAs) - and in particular on the oxacillinase-48 (OXA-48).

The class D SBLs are characterized by a hydrophobic environment in the active site, that facilitates the carboxylation of a lysine residue. The $\mathrm{N}$-carboxylated lysine plays a critical role in the substrate hydrolysis (10). Originally, the OXAs were believed to have a limited substrate profile only hydrolysing penicillins, but with the emergence of carbapenem- 
hydrolysing OXA variants, e.g. OXA-23, OXA-24 and OXA-48, their clinical relevance has increased (11). OXA-48 was reported for the first time in 2001 and has since then spread rapidly across the world. (11) It is commonly identified in Escherichia coli and Klebsiella pneumoniae.

One strategy to circumvent resistance in $\beta$-lactamase producing pathogens is the use of $\beta$ lactamases inhibitors $(4,12)$ in combination with the $\beta$-lactam antibiotic. Inhibitors of class $A$ SBLs like clavulanic acid, sulbactam and tazobactam became clinically available from the 1980s (13), but only a few class $D \beta$-lactamases are inhibited by these $\beta$-lactamase inhibitors e.g. OXA-2 and OXA-18 (14). In 2015, a new SBL inhibitor, avibactam, targeting class A, C and some class D SBLs, including OXA-48, was approved by the FDA for treatment of complicated urinary tract and intra-abdominal infections (15). However, the inhibition level of different class $D \beta$-lactamases by avibactam varies $(16,17)$. With the first reports of resistance to avibactam published (18), one can speculate that it will only be a matter of time before class D $\beta$-lactamases show resistance to avibactam as well.

The development of new OXA inhibitors, either with a different enzyme-inhibition profile compared to existing inhibitors, or as alternative when resistance to existing inhibitors arises, is of importance. We have previously reported a fragment-based screening approach to identify weak inhibitors of OXA-48 (19). The most interesting hit was 3-(pyridin-4yl)benzoic acid 1 with an $\mathrm{IC}_{50}$ of $250 \mu \mathrm{M}$ and a ligand efficiency (LE) of 0.32 . Crystallographic data from enzyme-fragment complexes indicated two overlapping binding conformations of the fragment. Merging of the two conformations of $\mathbf{1}$ into one molecule $\mathbf{2}$ (Fig. 1) gave a 10fold increase in binding affinity improving the IC $C_{50}$ from $250 \mu \mathrm{M}$ to $18 \mu \mathrm{M}$ (19).
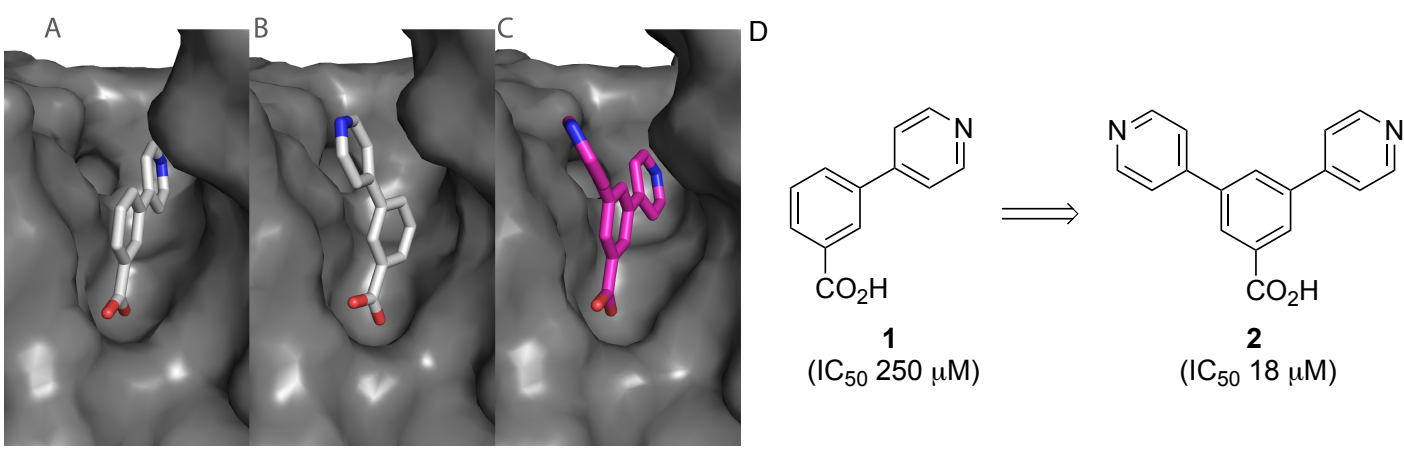

Figure 1: The two alternate conformations of fragment 1 (light grey) in complex with OXA-48 (dark grey surface) (A and B), the merged compound 2 (pink) in complex with OXA-48 (dark grey surface) (C), and a schematic view of the merging approach described in previous work (D) (19).

In this study, we describe the use of small mono-substituted fragments - analogues of fragment 1 - as probes to explore the OXA-48 binding site. The aim was to identify fragmentenzyme interactions in the two alternate binding pockets of the active site of OXA-48, which could be of general interest for the design of OXA-48 inhibitors. We wanted to exploit the ability of small fragments to efficiently explore the binding pocket as they are less restricted by size and more flexible compared to more elaborated inhibitors. Moreover, the smaller fragments generally have the advantage of being more easily prepared making the discovery 
process more work-efficient. Furthermore, we wanted to translate the knowledge gained into the rational design of di-substituted inhibitors related to compound $\mathbf{2}$ circumventing the laborious preparation of a large library of elaborated inhibitors.

Towards this goal, we prepared a focused fragment library containing 3-aryl benzoic acids decorated with a wide range of polar groups and a number of 3-heteroaryl benzoic acid derivatives. In total 49 fragments were tested for inhibitory activity against OXA-48 and the binding conformations of 33 fragment-enzyme complexes were analysed by X-ray crystallography. Based on the structural information, fragments could be classified according to their preferred binding pocket and useful fragment-enzyme interactions e.g. hydrogen bonds were identified. Moreover, several new orthogonally binding fragments were found leading to the design of symmetrically and unsymmetrically di-substituted inhibitors with improved $I_{50}$ in the low micromolar range. The structural data from enzyme-inhibitor complexes was compared with enzyme-fragment complexes.

\section{Results and discussion}

\subsection{Synthesis}

\subsubsection{Synthesis of 3-substituted benzoic acids}

A fragment library containing 49 3-substituted benzoic acid analogues 3a-35 was prepared (Table 1). The fragments generally fulfilled the demands of libraries for fragment-based ligand design ( $\mathrm{MW}<300$, clogP $<3$, hydrogen bond acceptor/donors <3) (20). For the synthesis, a strategy based on the Suzuki-Miyaura (SM) cross-coupling reaction to join two $\mathrm{sp}^{2}$-hybridized carbons was employed (21). Two alternate coupling strategies were successful starting with either 3-bromobenzoic acid (Table 1, strategy A) or 3carboxyphenylboronic acid pinacol ester (Table 1, strategy B) as starting materials allowing for the utilisation of a wide range of aryl boronic acids or aryl bromides to introduce diversity in the library.

Many of the required aryl boronic acids and bromides were commercial available, while the aryl bromides used as starting materials for fragments 17-20, 24, 29 and $\mathbf{3 0}$ were prepared according to standard acylation and sulphonylation protocols. The $\mathrm{NH}$-tetrazol-5-ylsubstituted arylbromides (starting material for fragments $\mathbf{2 6 a}$ and $\mathbf{2 6 b}$ ) were prepared by a [3+2] intermolecular cycloaddition of 3- or 4-bromobenzonitrile with trimethyl silyl azide in the presence of dibutyltin oxide in anhydrous 1,4-dioxane. The reaction mixture was subjected to microwave irradiation in a tightly sealed vessel for $50 \mathrm{~min}$ at $150^{\circ} \mathrm{C}$ to afford 3 or 4-bromobenzotetrazole in $86 \%$ and $82 \%$ yield, respectively. 

acids analogues against OXA-48 (IC $50, K_{d}$ and LE).

141

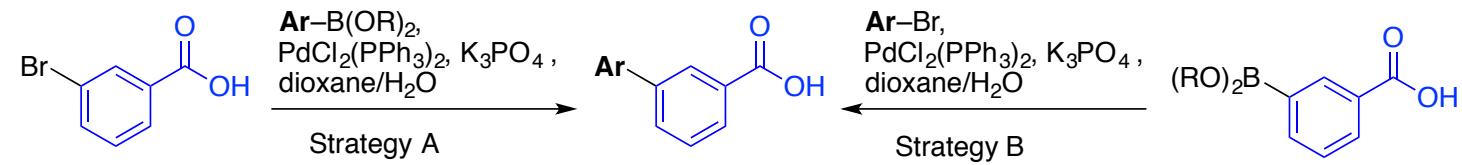

\begin{tabular}{|c|c|c|c|c|c|c|c|c|c|c|c|}
\hline $\begin{array}{c}\text { Comp. } \\
\text { ID }\end{array}$ & $\mathrm{Ar}=$ & $\begin{array}{c}\text { Strateg. } \\
\text { Yield }\end{array}$ & $\begin{array}{c}\mathrm{I}_{50} \\
(\mu \mathrm{M}) \\
\end{array}$ & $\begin{array}{c}\mathrm{K}_{\mathrm{D}} \\
(\mu \mathrm{M}) \\
\end{array}$ & $\mathrm{LE}^{\mathrm{d}}$ & $\begin{array}{c}\text { Comp. } \\
\text { ID }\end{array}$ & $A r=$ & $\begin{array}{c}\text { Strateg. } \\
\text { Yield }\end{array}$ & $\begin{array}{c}\begin{array}{c}\mathrm{C}_{50} \\
(\mu \mathrm{M})\end{array} \\
\end{array}$ & $\begin{array}{c}K_{D} \\
(\mu \mathrm{M}) \\
\end{array}$ & $\mathrm{LE}^{\mathrm{d}}$ \\
\hline $3 a^{*}$ & & $\begin{array}{c}\text { B } \\
78 \%\end{array}$ & 90 & 170 & 0.35 & $11 b^{*}$ & & $\begin{array}{c}A \\
97 \%\end{array}$ & 180 & 350 & 0.29 \\
\hline $3 \mathbf{b}^{*}$ & & $\begin{array}{c}B \\
67 \%\end{array}$ & 170 & 300 & 0.33 & $12 a^{*}$ & & $\begin{array}{c}A \\
82 \%\end{array}$ & 120 & 150 & 0.29 \\
\hline $4 a^{*}$ & & $\begin{array}{c}A \\
94 \%\end{array}$ & 50 & 175 & 0.38 & $12 b$ & & $\begin{array}{c}A \\
90 \%\end{array}$ & 380 & 361 & 0.25 \\
\hline $4 b *$ & & $\begin{array}{c}A \\
98 \%\end{array}$ & 110 & 110 & 0.35 & $13^{*}$ & & $\begin{array}{c}\text { B } \\
35 \%\end{array}$ & 330 & 330 & 0.29 \\
\hline $4 c^{*}$ & & $\begin{array}{c}\text { A } \\
39 \%\end{array}$ & 470 & 170 & 0.29 & $14^{*}$ & & $\begin{array}{c}A \\
95 \%\end{array}$ & 390 & 220 & 0.27 \\
\hline $5^{*}$ & & $\begin{array}{c}A \\
84 \%\end{array}$ & 900 & 230 & 0.25 & $15 a$ & & $\begin{array}{c}\text { B } \\
36 \%\end{array}$ & 600 & 800 & 0.27 \\
\hline $6 a^{*}$ & & $\begin{array}{c}\text { A } \\
98 \%\end{array}$ & 250 & 123 & 0.30 & $15 b$ & & $\begin{array}{c}\text { B } \\
86 \%\end{array}$ & 1400 & 550 & 0.23 \\
\hline $6 b^{*}$ & & $\begin{array}{c}A \\
98 \%\end{array}$ & 360 & 226 & 0.28 & $16 a$ & & $\begin{array}{c}B \\
15 \%\end{array}$ & 110 & 300 & 0.31 \\
\hline $6 c^{*}$ & & $\begin{array}{c}A \\
86 \%\end{array}$ & 150 & 250 & 0.31 & 16b & & $\begin{array}{c}B \\
67 \%\end{array}$ & 1000 & 970 & 0.23 \\
\hline 7 & & $\begin{array}{c}A \\
91 \%\end{array}$ & 400 & 1000 & 0.28 & $17 *$ & & $\begin{array}{l}B^{a, c} \\
41 \%\end{array}$ & 370 & 100 & 0.24 \\
\hline $8 a^{*}$ & & $\begin{array}{c}A \\
68 \%\end{array}$ & 130 & 170 & 0.34 & 18 & & $\begin{array}{l}\mathrm{B}^{\mathrm{a}, \mathrm{c}} \\
65 \%\end{array}$ & 60 & 210 & 0.24 \\
\hline $8 b^{*}$ & & $\begin{array}{c}A \\
98 \%\end{array}$ & 130 & 240 & 0.34 & 19a & & $\begin{array}{l}B^{a, c} \\
26 \%\end{array}$ & 110 & 110 & 0.26 \\
\hline $8 c^{*}$ & & $\begin{array}{c}A \\
78 \%\end{array}$ & 360 & 312 & 0.30 & $19 b$ & & $\begin{array}{l}\mathrm{B}^{\mathrm{a}, \mathrm{c}} \\
10 \%\end{array}$ & 450 & 240 & 0.22 \\
\hline $9 a$ & & $\begin{array}{l}A^{a, c}, \\
57 \%\end{array}$ & 210 & 200 & 0.27 & 20 & & $\begin{array}{l}\mathrm{B}^{\mathrm{a}, \mathrm{c}} \\
11 \%\end{array}$ & 370 & 200 & 0.22 \\
\hline $9 b^{*}$ & & $\begin{array}{c}A \\
54 \%\end{array}$ & 260 & 144 & 0.26 & $21 a^{*}$ & & $\begin{array}{c}A \\
98 \%\end{array}$ & 35 & 100 & 0.33 \\
\hline 10 & & $\begin{array}{c}\text { A } \\
98 \%\end{array}$ & 380 & 280 & 0.27 & $21 b^{*}$ & & $\begin{array}{c}\text { A } \\
98 \%\end{array}$ & 450 & 290 & 0.25 \\
\hline 11a & & $\begin{array}{c}\text { A } \\
98 \%\end{array}$ & 260 & 220 & 0.28 & 22 & & $\begin{array}{l}B^{a, b} \\
87 \%\end{array}$ & 130 & 130 & 0.27 \\
\hline
\end{tabular}

* X-ray structure of fragment-enzyme complex available. ${ }^{a}$ Reaction in anhydrous THF instead of dioxane:water as solvent; ${ }^{b}$ XPhos-Pd G2 as catalyst instead of $\mathrm{PdCl}_{2}\left(\mathrm{PPh}_{3}\right)_{2} ;{ }^{\mathrm{C}} \mathrm{PdCl}_{2}(\mathrm{dppf})$ as catalyst instead of $\mathrm{PdCl}_{2}\left(\mathrm{PPh}_{3}\right)_{2} \cdot{ }^{\mathrm{d}} \mathrm{LE}=\left(-1.4 * \log _{10} \mathrm{IC}_{50}\right) /$ HeavyAtomCount with units $\mathrm{kcal} /(\mathrm{mol}$ per heavy atom). 


\begin{tabular}{|c|c|c|c|c|c|c|c|c|c|c|c|}
\hline $\begin{array}{l}\text { Comp. } \\
\text { ID }\end{array}$ & $\mathrm{Ar}=$ & $\begin{array}{c}\text { Strateg. } \\
\text { Yield }\end{array}$ & $\begin{array}{c}\mathrm{IC}_{50} \\
(\mu \mathrm{M}) \\
\end{array}$ & $\begin{array}{c}K_{D} \\
(\mu \mathrm{M})\end{array}$ & $\mathrm{LE}^{\mathrm{d}}$ & $\begin{array}{c}\text { Comp. } \\
\text { ID }\end{array}$ & $\mathrm{Ar}=$ & $\begin{array}{c}\text { Strateg. } \\
\text { Yield }\end{array}$ & $\begin{array}{c}I_{50} \\
(\mu \mathrm{M}) \\
\end{array}$ & $\begin{array}{c}\mathrm{K}_{\mathrm{D}} \\
(\mu \mathrm{M})\end{array}$ & $\mathrm{LE}^{\mathrm{d}}$ \\
\hline $23 a$ & & $\begin{array}{l}B^{a, c} \\
46 \%\end{array}$ & 230 & 170 & 0.24 & 29 & & $\begin{array}{c}\text { B } \\
36 \%\end{array}$ & 170 & 130 & 0.33 \\
\hline $23 b$ & & $\begin{array}{c}B^{a, c} \\
34 \%\end{array}$ & 520 & 190 & 0.22 & 30 & & $\begin{array}{c}B \\
45 \%\end{array}$ & 800 & 900 & 0.29 \\
\hline $24^{*}$ & & $\begin{array}{l}A^{a, b} \\
34 \%\end{array}$ & 250 & 140 & 0.25 & 31 & & $\begin{array}{c}\text { B } \\
67 \%\end{array}$ & 350 & 113 & 0.28 \\
\hline 25 & & $\begin{array}{c}B \\
15 \%\end{array}$ & 1300 & $>1000$ & 0.20 & 32 & & $\begin{array}{c}A \\
6 \%\end{array}$ & 500 & 590 & 0.31 \\
\hline $26 a *$ & & $\begin{array}{c}\text { B } \\
98 \%\end{array}$ & 60 & 70 & 0.30 & 33 & & $\begin{array}{c}\text { B } \\
24 \%\end{array}$ & 800 & 900 & 0.31 \\
\hline $26 b$ & & $\begin{array}{c}\text { B } \\
98 \%\end{array}$ & 36 & 70 & 0.30 & 34 & & $\begin{array}{c}B \\
20 \%\end{array}$ & 310 & 400 & 0.27 \\
\hline $27^{*}$ & & $\begin{array}{c}B \\
67 \%\end{array}$ & 110 & 400 & 0.30 & $35^{*}$ & & $\begin{array}{c}\text { A } \\
98 \%\end{array}$ & 35 & 159 & 0.42 \\
\hline $28^{*}$ & & $\begin{array}{c}\text { B } \\
87 \%\end{array}$ & 240 & 160 & 0.27 & & & & & & \\
\hline
\end{tabular}

* X-ray structure of fragment-enzyme complex available. ${ }^{\text {a }}$ Reaction in anhydrous THF instead of dioxane:water as solvent; ${ }^{\mathrm{b}} \mathrm{XPhos}-\mathrm{Pd} \mathrm{G} 2$ as catalyst instead of $\mathrm{PdCl}_{2}\left(\mathrm{PPh}_{3}\right)_{2} ;{ }^{\mathrm{c}} \mathrm{PdCl}_{2}(\mathrm{dppf})$ as catalyst instead of $\mathrm{PdCl}_{2}\left(\mathrm{PPh}_{3}\right)_{2}$. ${ }^{\mathrm{d}} \mathrm{LE}=\left(-1.4 * \log _{10} \mathrm{IC}_{50}\right) /$ HeavyAtomCount with units $\mathrm{kcal} /(\mathrm{mol}$ per heavy atom).

In general, couplings under standard aqueous conditions using $\mathrm{PdCl}_{2}\left(\mathrm{PPh}_{3}\right)_{2}$ as catalyst (5-10 mol\%), $\mathrm{K}_{3} \mathrm{PO}_{4}$ as base (5 equiv.) in dioxane/water gave good yields. The couplings leading to fragments 9, 17-20 and 22-24 were not successful under these standard conditions. More efficient catalysts (XPhos-Pd G2 or $\mathrm{PdCl}_{2}(\mathrm{dppf})$ ) and water-free conditions (anhydrous THF instead of dioxane/water) were successfully employed to solve reactivity and solubility problems and to prevent hydrolysis for base sensitive products (9 and 24). However, for some products $(\mathbf{1 9 a}+\mathbf{b}$ and $\mathbf{2 0})$ the yields were still low $(<20 \%)$. Generally, the reactions were easily purified by automated C18 flash chromatography to provide compounds of high purity (>95\% as determined by UHPLC). For some compounds (15, 16, 19, 23, 24, 32 and 34), additional silica flash chromatography was necessary to provide sufficiently pure products.

\subsubsection{Synthesis of 3,5-disubstituted benzoic acid derivatives.}

To study inhibitor properties like activity and enzyme interactions of merged fragments, a small series of symmetrical and unsymmetrical 3,5-disubstituted benzoic acids was designed (vide infra) and prepared. The synthesis of symmetrical 3,5-disubstituted compounds $\mathbf{3 6}$ and 38 was achieved under the conditions established for the coupling of mono-substituted fragments using $\mathrm{Pd}_{2}(\mathrm{dba})_{3} / X P$ hos or XPhos-Pd G2 as catalysts (Scheme 1) (19). The disubstituted coupling products $\mathbf{3 6}$ and $\mathbf{3 8}$ were obtained from 3,5-dibromobenzoic acid as starting material and an increased amount of the boronic acid derivative (2 equiv.) in 54\% and $65 \%$ yield, respectively. Compound $\mathbf{3 7}$ was isolated in $11 \%$ yield as by-product in an attempt to selectively mono-substituted 3,5-dibromobenzoic acid (vide infra). 


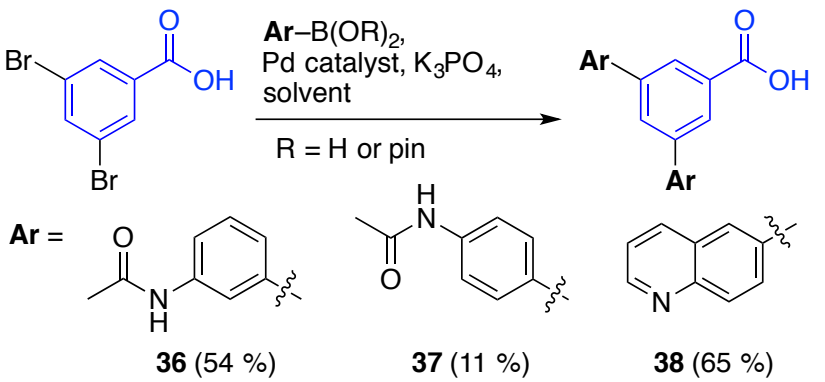

Scheme 1. Preparation of symmetrical 3,5-disubstituted benzoic acids. Reagents and conditions: 36: 3-acetamidophenylboronic acid (1.5 equiv.), $\mathrm{Pd}_{2}\left(\mathrm{dba}_{3}{ }_{3} \mathrm{CHCl}_{3}\left(5 \mathrm{~mol}^{\circ}\right), \mathrm{XPhos}\right.$ (5 mol\%), dioxane:water (1:1), $60{ }^{\circ} \mathrm{C}, 54 \%$; 37: 4-acetamidophenylboronic acid (0.75 equiv.), $\mathrm{PdCl}_{2}\left(\mathrm{PPh}_{3}\right)_{2}(10 \mathrm{~mol} \%)$, dioxane:water (1:1), $95^{\circ} \mathrm{C}, 11 \%$; 38: quinolin-6-ylboronic acid pinacol ester (2.0 equiv.), XPhos-Pd G2 (5 mol\%), tert-butanol, $60{ }^{\circ} \mathrm{C}, 65 \%$.

For the synthesis of unsymmetrical 3,5-disubstituted benzoic acids 39, the sequential addition of two different aryl boronic acids under the previously established conditions gave only $15 \%$ isolated yield (Scheme 2 ). In addition, the procedure involved tedious HPLC purifications as the reaction mixture was difficult to purify due to occurrence of symmetrical by-products with similar properties. To improve the selectivity of the reaction, we changed the starting material from 3,5-dibromobenzoic acid to 3-iodo-5-bromobenzoic acid in order to take advantage of the faster coupling reaction of aryl iodides when compared with aryl bromides and thereby to prevent formation of symmetrical disubstituted by-products (Scheme 2). Investigation of the chemoselective coupling of 3-iodo-5-bromobenzoic acid with quinolin-6ylboronic acid pinacol ester to form mono-substituted int-40 showed that a second, unwanted coupling was not easily prevented and a careful fine tuning of catalyst (RuPhos-Pd G3, XantPhos-Pd G3, Sphos/Pd $\left(\mathrm{dba}_{3}\right.$, Xphos/Pd $2(\mathrm{dba})_{3}$, SPhos-Pd G3, XPhos-Pd $\mathrm{G} 2, \mathrm{Pd}_{2}(\mathrm{dppf}) \mathrm{Cl}_{2}$ ), solvent (toluene/water, anhydrous THF, dioxane/water, tert-butanol), reaction temperature $\left(40-80^{\circ} \mathrm{C}\right)$ and time $(10-48 \mathrm{~h}$ ) was initiated (Table SI1, see supporting information). The composition of the crude reaction mixtures with respect to mono- and disubstituted products as well as unreacted starting material was determined by mass spectrometry (MS). The most chemoselective catalysts were XantPhos-Pd G3, $\mathrm{Pd}_{2}(\mathrm{dppf}) \mathrm{Cl}_{2}$ and $\mathrm{SPhos} / \mathrm{Pd}_{2}(\mathrm{dba})_{3}$ showing good selectivity for the aryl iodide when the reaction was performed with $\mathrm{K}_{3} \mathrm{PO}_{4}$ as base in dioxane/water at $60{ }^{\circ} \mathrm{C}$ for 24 hours (Scheme 2). At this conditions with $\mathrm{SPhos} / \mathrm{Pd}_{2}(\mathrm{dba})_{3}$ as catalyst, the monosubstituted intermediate int-40 was obtained as main product together with small amounts of the disubstituted by-product (8$10 \%)$. Careful purification to remove any traces of the disubstituted compound provided int$\mathbf{4 0}$ in moderate yield (45\%). The mono-substituted int-40 was further subjected to a second coupling with XPhos-Pd G2 (5 mol\%) as catalyst to provide 40 in good yields (90\%). 


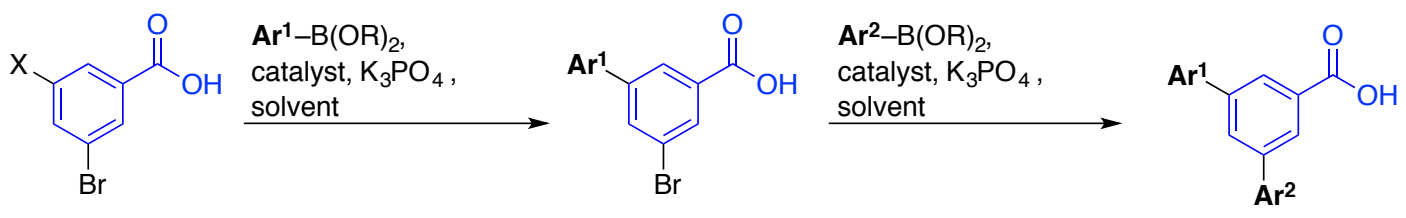

$\operatorname{Ar}^{1}=$<smiles>CC(=O)Nc1cccc(C)c1</smiles>

int-39 (not isolated)

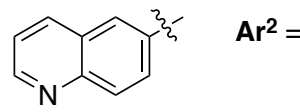

int-40 (45\%)<smiles>Cc1ccncc1</smiles>

39 (11\%)<smiles>CC(=O)Nc1cccc(C)c1</smiles>

40 (90\%)

Scheme 2: Preparation of unsymmetrical 3,5-disubstituted benzoic acids. Reagents and conditions: 39: i. $X=B r$, 3-acetamidophenylboronic acid (0.75 equiv.), $P d C_{2}\left(P^{2} \mathrm{Ph}_{3}\right)_{2}(10 \mathrm{~mol} \%)$, dioxane:water (1:1), $60{ }^{\circ} \mathrm{C}$; ii. pyridin-4-ylboronic acid (1.2 equiv.), $\mathrm{PdCl}_{2}\left(\mathrm{PPh}_{3}\right)_{2}\left(10 \mathrm{~mol}^{\circ}\right)$, dioxane:water (1:1), $60^{\circ} \mathrm{C}$; int-40: $X=1$, quinolin-6-ylboronic acid pinacol ester (2.0 equiv.), $\mathrm{Pd}_{2}(\mathrm{dba})_{3} \mathrm{CHCl}_{3}$ (5 mol\%), SPhos (5 mol\%), dioxane:water (1:1), $60{ }^{\circ} \mathrm{C}$; 40: 3acetamidophenylboronic acid (1.5 equiv.), XPhos-Pd G2 (5 mol\%), tert-BuOH, $60{ }^{\circ} \mathrm{C}$.

\subsection{Evaluation of 3-substituted benzoic acids}

\subsubsection{Inhibitor activity of 3-substituted benzoic acids}

The mono-substituted fragments 3-35 were initially investigated for their inhibitory activity against OXA-48 in an enzymatic assay and by SPR. Inhibition and binding data are given in Table 1 along with the associated ligand efficiencies (LE). The original hit fragment 1 had an $\mathrm{IC}_{50}$ of $250 \mu \mathrm{M}$ and an LE of 0.32. Most of the fragments in this study showed inhibition at a similar level with $\mathrm{IC}_{50}>200 \mu \mathrm{M}$ and $\mathrm{LE} \leq 0.30$. Fragments $4 \mathrm{a}\left(\mathrm{IC}_{50}(\mu \mathrm{M}) / \mathrm{LE}: 50 / 0.38\right), 18\left(\mathrm{IC}_{50}\right.$ $(\mu \mathrm{M}) / \mathrm{LE}: 60 / 0.24)$, 21a $\left(\mathrm{IC}_{50}(\mu \mathrm{M}) / \mathrm{LE}: 35 / 0.33\right), 26 \mathbf{b}\left(\mathrm{IC}_{50}(\mu \mathrm{M}) / \mathrm{LE}: 36 / 0.30\right)$ and $35\left(\mathrm{IC}_{50}\right.$ $(\mu \mathrm{M}) / \mathrm{LE}: 35 / 0.42)$ showed an order of magnitude stronger inhibition and were the most potent fragments. Even though there are some discrepancies between the inhibition and binding data, the same trends are maintained when comparing similar compounds, indicating that the compounds indeed bind specifically to one site of the enzyme.

\subsubsection{Structural analysis of 3-substituted benzoic acids}

To evaluate the binding poses of our fragments, enzyme-fragment complexes for x-ray crystallographic analysis were prepared. Rewardingly, 33 out of 49 fragments were successfully soaked with OXA-48 and yielded crystal structures with resolution high enough to warrant placement of the inhibitor in the electron density (Table 1). In addition, a crystal structure of OXA-48 in complex with the substrate imipenem was obtained to better understand substrate binding and to compare substrate and fragment binding interactions.

The crystal structure of the acyl-enzyme complex of OXA-48 with imipenem (Fig. 2A) revealed a conformation close to previously observed conformations with OXA-13 (PDB-ID: 1h5x). In the complex the ring-opened imipenem was bound to OXA-48 covalently with continuous electron density from the hydroxyl group of Ser70. There was an ionic bond from the carboxylate group of imipenem to the guanidine group of Arg250. The carbonyl-group of the now ring-opened $\beta$-lactam ring was positioned in the oxyanion-hole forming hydrogen bonds to the main chain amides of Tyr211 and Ser70. The $6 \alpha$-hydroxyethyl group $\left(R^{1}\right)$ of imipenem was positioned towards the hydrophobic residues Trp105, Val120 and Leu158 and in the following discussion this region will be called the $R^{1}$ site. The amidine group $\left(R^{2}\right)$ was 
situated in the cleft defined by Ile102, Tyr211, Leu247 and Thr213 and this region will be called the $R^{2}$ site. The $R^{1}$ and $R^{2}$ side chains of imipenem (Fig. $2 A$ ) had the same overall directions as the pyridinyl substituents in the two overlapping binding conformations observed with our initial hit 3-pyridin-4-ylbenzoic acid 1 (19).

In all our structures of OXA-48 in complex with fragments, an ionic bond between the carboxylate group of the fragments and the guanidine group of Arg250 was observed, which resembled the interaction of the carboxylate group of imipenem or the sulfamate group of avibactam with $\operatorname{Arg} 250 .(17,22)$ In some cases, the carboxylate group was oriented in such a way that also Thr209 (fragments 9b, 28, 35), Lys208 (fragment 34) or both (fragment 26a) participated in binding.

Another common feature found in almost all crystal structures, except for fragments 21a and $\mathbf{2 6}$, was a $\pi$ - $\pi$ stacking interaction of the 3-aryl substituents attached to the benzoic acid scaffold with Tyr211. This is consistent with the binding of imipenem, where the $R_{2}$ side chain was oriented towards Tyr211 (Fig. 2C). The importance of Tyr211 as a non-polar patch that contributes in binding substrate side-chains has been recognised before (23). We also observed this interaction with our unsubstituted pyridyl benzoic acids previously. (19)
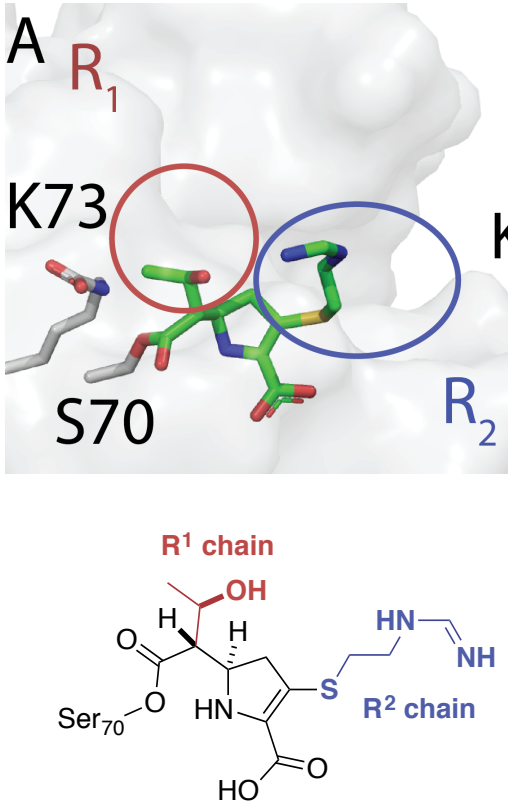
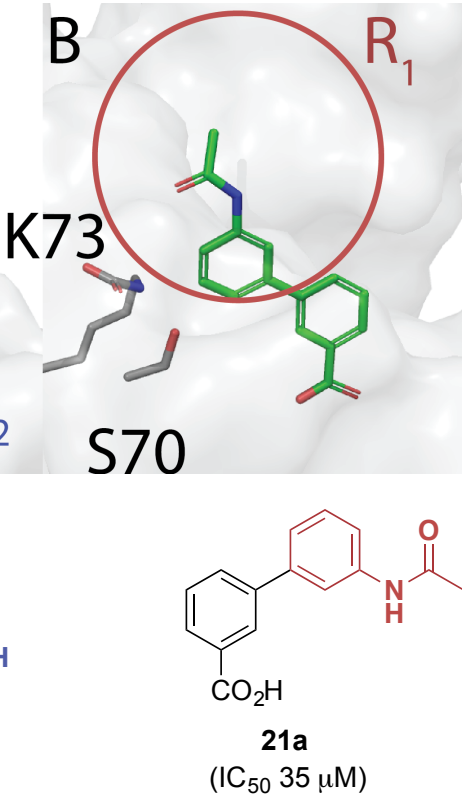
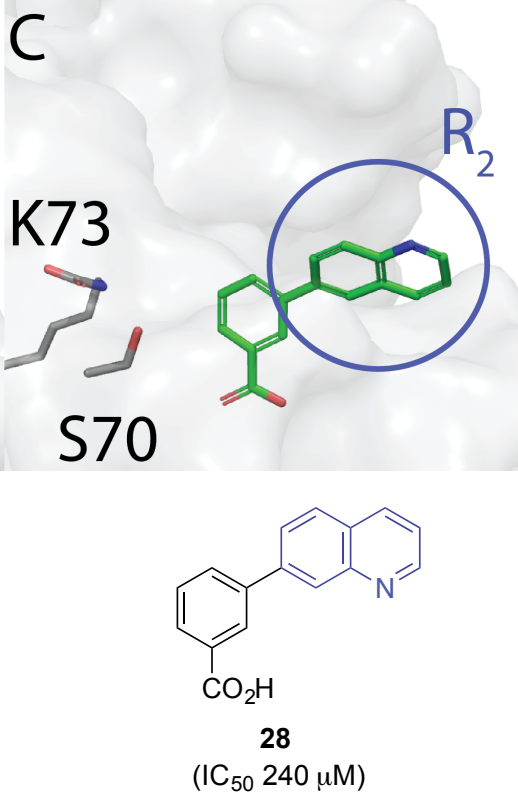

Figure 2: The crystal structure of imipenem in complex with OXA-48 (A) shows that the two side chains of imipenem extends in separate directions. The carbapenem substrates of OXA48 have small $R^{1}$ side chains. We were however able to fit larger groups in the $R^{1}$ site like the $\mathrm{N}$-acetamide substituted phenyl ring in compound 21a (B). Yet, most of the tested 3substituted benzoic acids bind towards the larger $R^{2}$ site, like the quinolin-7-yl substituted compound 28 (C).

The weaker binding fragments (3a+b, 4a-c, 5, 6a-c, 8a-c, 9b, 11b, 12a, 13, 14, 17, 24) all bound in nearly the same conformation with the ionic bond of the benzoic acid and Arg250 and the $\pi-\pi$ stacking interaction with Tyr211 as major interactions. In these structures, the 3aryl substituent on the benzoic acid was directed towards the $\mathrm{R}_{2}$ pocket (Fig. $2 \mathrm{C}$ ). Only minor conformational differences were observed as described in the following. To help the reader 
in the following discussion, we will describe the fragments by the identity of the Ar groups (Table 1), as the structural differences of the fragments relate to this group i.e. 3-(2methyl)phenylbenzoic acid 3a will be described as 2-methylphenyl substituted fragment.

The methylphenyl substituted fragments $3 \mathbf{3 a}\left(\mathrm{IC}_{50}(\mu \mathrm{M}) / \mathrm{LE}: 90 / 0.35\right)$ and $\mathbf{3 b}\left(\mathrm{IC}_{50}(\mu \mathrm{M}) / \mathrm{LE}\right.$ : $170 / 0.33$ ) had similar conformations, however, the 2-methyl group in 3a was facing towards the hydrophobic $\mathrm{C}^{\beta}$ of Ser244 explaining the more favourable binding. Fragments $4 a-c\left(I C_{50}\right.$ $(\mu M) / L E: 50 / 0.38,110 / 0.35$ and $470 / 0.29$, respectively) also had very similar conformations, but again we saw that more favourable van der Waals interactions gave higher affinity for the 2-hydroxyphenyl substituted $\mathbf{4 a}$. The 4-hydroxy isomer $\mathbf{4 c}$ had an unfavourable solvent exposure of the hydroxyl group. Adding a methylene bridge yielding 3-hydroxymethylphenyl $5\left(\mathrm{IC}_{50}(\mu \mathrm{M}) / \mathrm{LE}: 900 / 0.25\right)$ did not lead to any favourable interactions. The methoxyphenyl fragments 6a-c $\left(\mathrm{IC}_{50}(\mu \mathrm{M}) / \mathrm{LE}: 250 / 0.30,360 / 0.28\right.$ and 150/0.31) shared the canonical $\mathrm{R}^{2}$ binding pose. The methoxy group of the 2-substituted 6 a appeared more shielded from solvent exposure than in $\mathbf{6 b}$ and $\mathbf{6 c}$, yet the methoxy group did not seem to make any strong contacts. The weak inhibition seen with methyl thioether 7 (IC $\left.5_{50}(\mu \mathrm{M}) / \mathrm{LE}: 400 / 0.28\right)$ corresponded to the results observed with the methoxy ethers 6 . The fluorophenyl substituted 8a-c $\left(\mathrm{IC}_{50}(\mu \mathrm{M}) / \mathrm{LE}: 130 / 0.34,130 / 0.34\right.$ and 360/0.30) had nearly identical binding poses. The 4 -substituted $\mathbf{8 c}$ gave the highest $\mathrm{IC}_{50}$ value, most likely due to the solvent exposed fluorine. The 2-substituted $8 \mathbf{a}$ seemed more favourable based on the decreased solvent exposure of the fluorine atom, however, the difference to $\mathbf{8 b}$ was negligible only observed by SPR.

The methoxyacetylphenyl esters 9a+b $\left(\mathrm{IC}_{50}(\mu \mathrm{M}) / \mathrm{LE}: 210 / 0.27\right.$ and $\left.260 / 0.26\right)$ showed no clear additional interactions in the complex structures with OXA-48, and the methyl group appeared to be unfavourably exposed to the solvent. The corresponding 4-acetylphenyl substituted $10\left(\mathrm{IC}_{50}(\mu \mathrm{M}) / \mathrm{LE}: 380 / 0.27\right)$ and carbamoylphenyl substituted 11a+b (IC 50 $(\mu M) / L E: 260 / 0.28$ and $180 / 0.29)$ gave generally weak inhibition indicating that a carbonyl group attached to the aromatic ring was not contributing to binding. No complex structures are available for $\mathbf{1 0}$ and 11a, but the complex structure of 4-carbamoylphenyl 11b was similar in conformation to the esters $\mathbf{9 a + b}$. Slightly tighter binding was observed with the meta-substituted sulfone $12 \mathrm{a}\left(\mathrm{IC}_{50}(\mu \mathrm{M}) / \mathrm{LE}: 120 / 0.29\right)$, which also shares the same overall conformation.

The 4-aminophenyl substituent of $\mathbf{1 3}\left(\mathrm{IC}_{50}(\mu \mathrm{M}) / \mathrm{LE}: 330 / 0.30\right)$ did not appear to make any interaction with the enzyme, and the inhibition was weak. The complex structure of the corresponding $N, N$-dimethyl-4-aminophenyl substituted 14 (IC $\left.C_{50}(\mu \mathrm{M}) / \mathrm{LE}: 390 / 0.27\right)$ showed that the two methyl groups are solvent exposed, and this is reflected in the poor inhibition by this compound. Similar to the complex structure of 14, the methyl 4-sulfonamidophenyl group of $\mathbf{1 7}\left(\mathrm{IC}_{50}(\mu \mathrm{M}) / \mathrm{LE}: 370 / 0.24\right)$ was seemingly pushed out of the active site and appears completely exposed to the solvent. The larger phenyl 4-sulfonamidophenyl substituted fragment $18\left(\mathrm{IC}_{50}(\mu \mathrm{M}) / \mathrm{LE}: 60 / 0.24\right)$ showed lower $\mathrm{IC}_{50}$ values probably driven by the increase in hydrophobicity, and no complex structure was obtained. 
The corresponding 4-acetamidophenyl 21b $\left(\mathrm{IC}_{50}(\mu \mathrm{M}) / \mathrm{LE}: 450 / 0.25\right)$ showed weak inhibition, likely due to the solvent exposure of the hydrophobic methyl group. The 3-acetamidophenyl containing fragment 21a (Figure 3), however, showed a 10-fold increased inhibition (IC 50 $(\mu \mathrm{M}) / \mathrm{LE}: 35 / 0.33)$. The complex structure of OXA-48 with fragment 21a revealed that the carbonyl of the acetyl formed a hydrogen bond to the guanidine group of Arg214, which directs the 3 -acetamidophenyl substituent to the $R^{1}$ site (Fig. $2 B$ ) and lead to a T-shaped $\pi-\pi-$ stacking interaction of the 3 -acetamidophenyl substituent with Trp105. The $\pi-\pi$ stacking of the 3-acetamidophenyl substituent to Tyr211 normally observed with these fragments was not observed; instead Tyr211 interacted with the benzoic acid by T-shaped $\pi$ - $\pi$-stacking. The interaction of an acetamide with Arg214 has been described previously for the avibactam analogue FPI-1523 in complex with OXA-48 (PDB-ID: 5fas) (22).
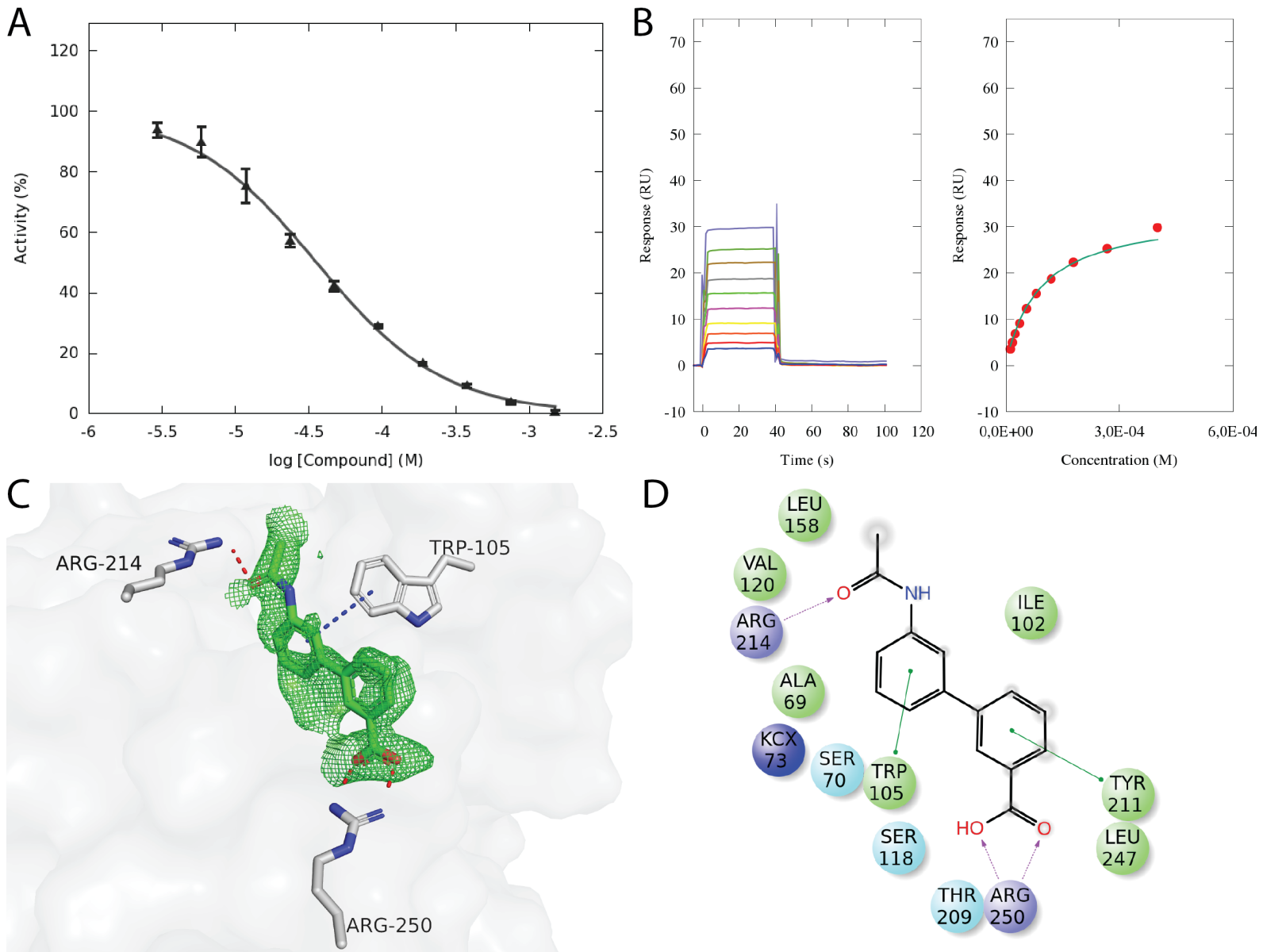

D

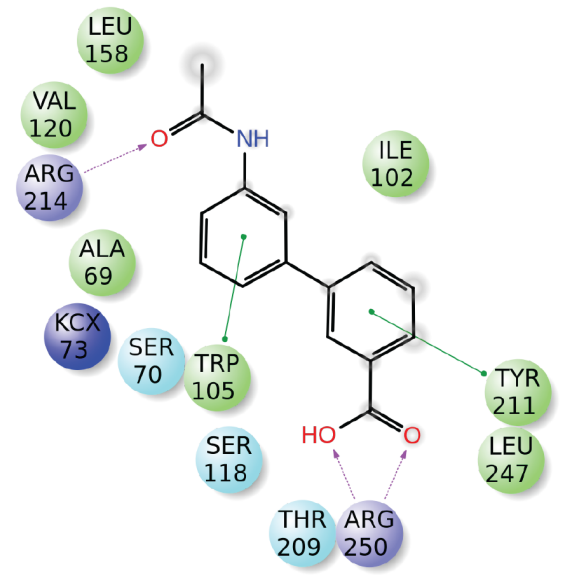

Figure 3: Compound 21a was one of the most potent 3-substituted benzoic acid derivatives we found. The $I C_{50}$-value $(A)$ was determined to be $35 \mu \mathrm{M}$, while the $K_{d}$ was found to be 100 $\mu M(B)$. The crystal structure of the complex OXA-48:21a with an omit-type polder-map $(2.5 \sigma)(C)$ and its 2D-representation (D) shows that the carbonyl of the acetamido-group forms a hydrogen bond with the guanidine of Arg214. The interaction with Arg214 causes the B-ring to move away from Tyr211, introducing a new interaction with Trp105.

Encouraged by the results for fragment 21a, we designed a series of fragments incorporating a hydrocarbon linker between the phenyl ring and the amino, sulfonamido or acetamido groups of 13,18 and $\mathbf{2 1}$. The amines 15 and 16, the sulfonamides 19 and 20, the amides 22 , $\mathbf{2 3} \mathbf{a}+\mathbf{b}$ and the acetate $\mathbf{2 4}$ are more flexible, thus, increasing the potential of hydrogen 
bonding. However, none of these fragments showed substantially improved binding (IC $\mathrm{C}_{50}$ : 110-1000; LE: 0.19-0.30). Moreover, the crystal structures of the amides 22, 23a+b and the acetate $24\left(\mathrm{IC}_{50}(\mu \mathrm{M}) / \mathrm{LE}: 230 / 0.24,520 / 0.22\right.$ and 250/0.25) did not show any specific interactions for the functional groups.

In fragments 26a and 26b $\mathrm{NH}$-tetrazole substituted phenyl rings were investigated as $\mathrm{Ar}$ substitutents. Introducing the weakly acidic tetrazol-5-ylphenyl substituent in either 3position 26a $\left(\mathrm{IC}_{50}(\mu \mathrm{M}) / \mathrm{LE}: 60 / 0.30\right)$ or 4-position $26 \mathrm{~b}\left(\mathrm{IC}_{50}(\mu \mathrm{M}) / \mathrm{LE}: 36 / 0.30\right)$ yielded good binding for both fragments. However, the binding poses for the two compounds were very different. The 3-tetrazol-5-ylphenyl substituted $\mathbf{2 6 a}$ bound in two alternate positions. The $\pi-$ $\pi$-stacking with Tyr211 was maintained for both conformations, but the tetrazoles appeared completely solvent exposed with no interactions with the enzyme. The 4-tetrazol-5-ylphenyl substituted 26b formed a hydrogen bond with the guanidine group of Arg214 (Fig. 4), interrupting the $\pi-\pi$-stacking with Tyr211. Fragment $\mathbf{2 6 b}$ occupied the $\mathrm{R}^{1}$ site rather than the more common $\mathrm{R}^{2}$ site.
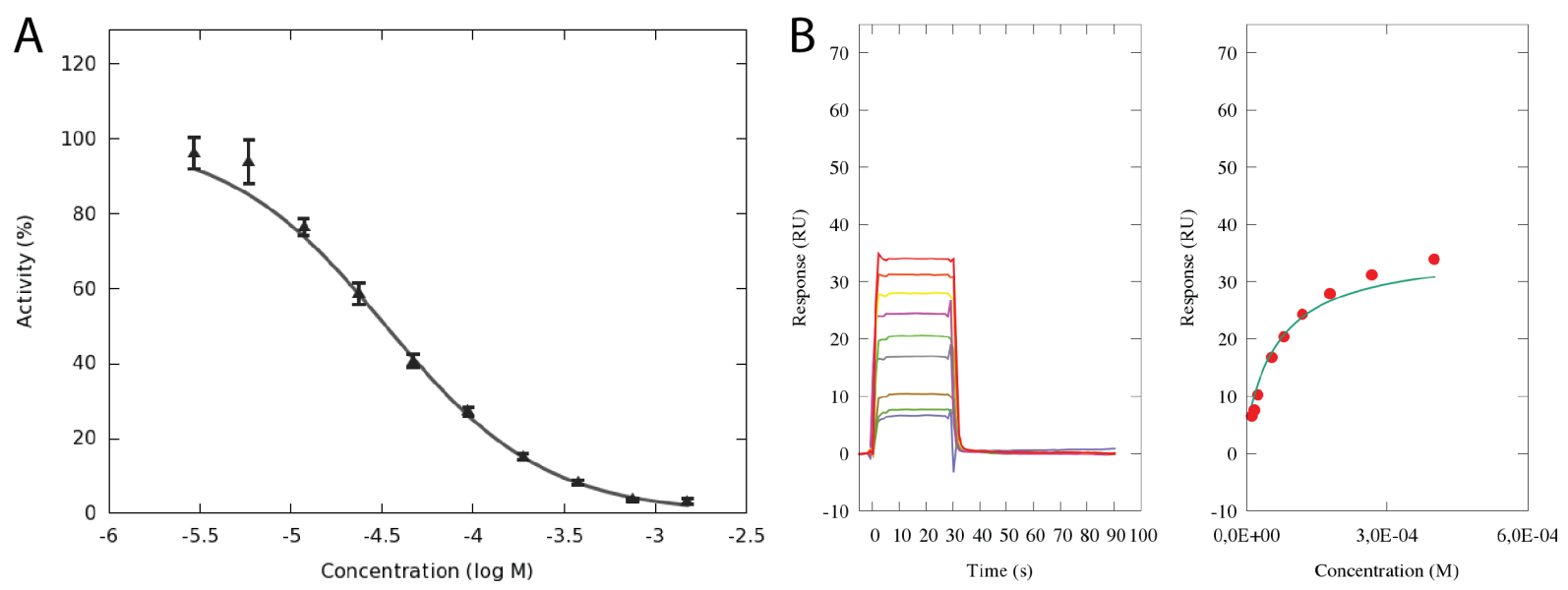

C
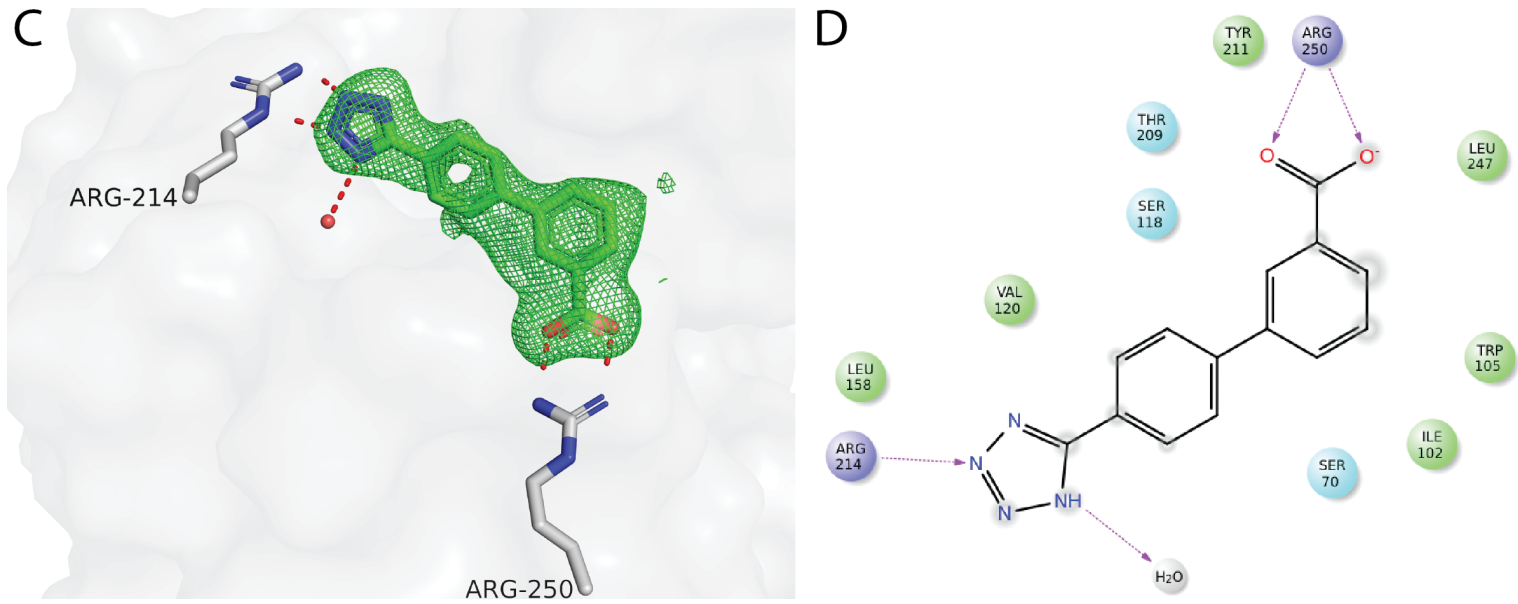

Figure 4: The $I C_{50}$-value of compound $26 \mathrm{~b}(\mathrm{~A})$ was determined to be $36 \mu \mathrm{M}$, while the $K_{D}$ was found to be $70 \mu M(B)$. The crystal structure of the complex OXA-48:26b with an omit-type polder-map (2.5\%) (C) and a 2D-representation of the protein:compound complex interactions. (D). 

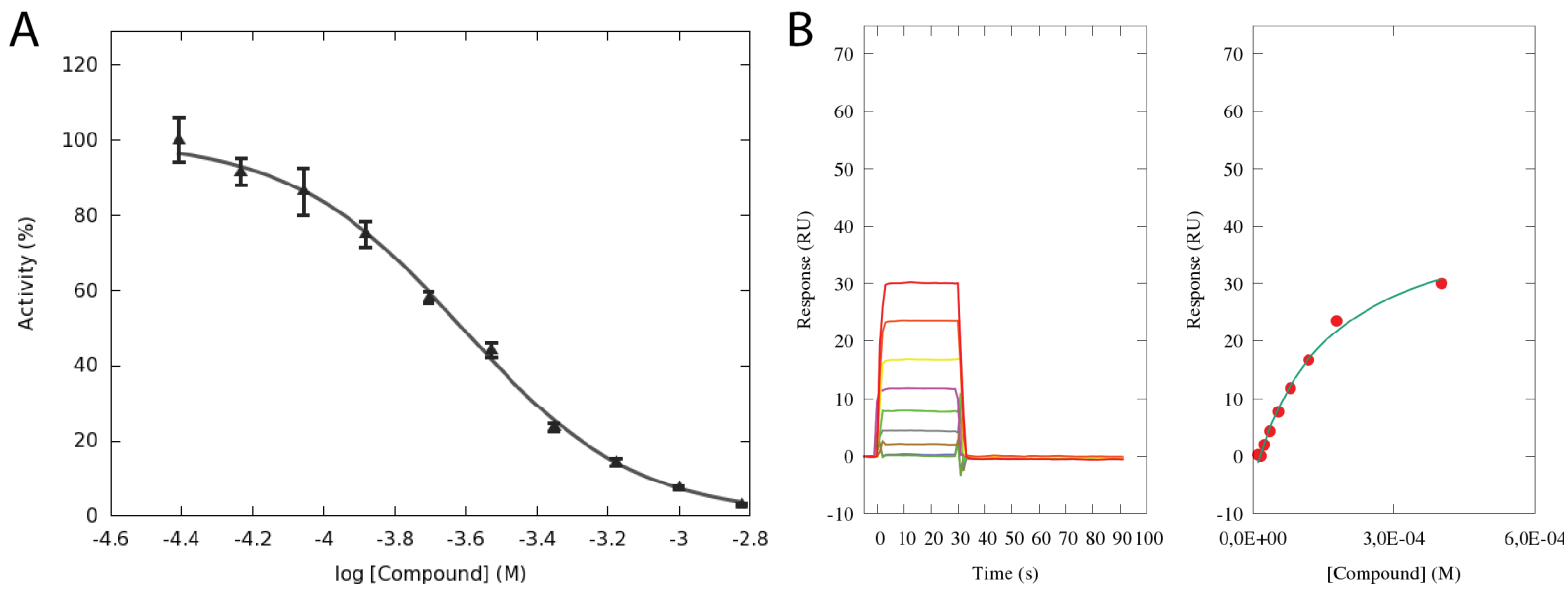

C

D
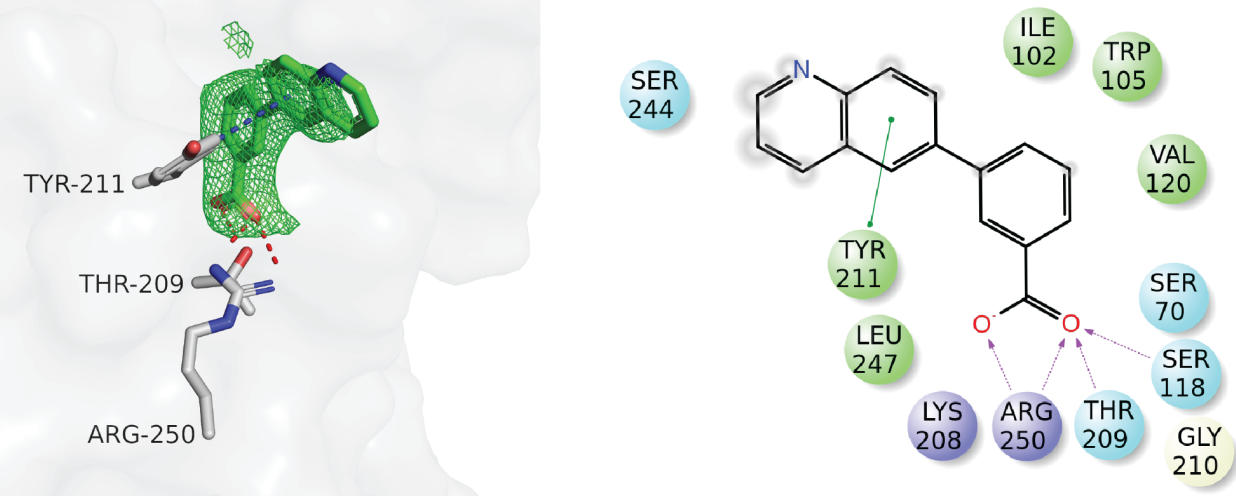

Figure 5: The $I C_{50}$-value of compound $28(A)$ was determined to be $240 \mu \mathrm{M}$, while the $K_{D}$ was found to be $160 \mu M(B)$. The crystal structure of the complex OXA-48:28 with an omit-type polder-map (2.5 $\sigma)$ (C) and a 2D-representation of the protein:compound complex interactions. (D).

A number of heterocyclic aryl substituents were also evaluated (fragments $25,28-35)$. With some exceptions of the pyridinyls 29 and $35\left(I C_{50}(\mu \mathrm{M}) / L E: 170 / 0.33\right.$ and 35/0.42) most of these fragments showed only weak inhibition. The quinolin-7-yl substituted fragment 28 $\left(\mathrm{IC}_{50}(\mu \mathrm{M}) / \mathrm{LE}: 240 / 0.30\right)$ did maintain the overall conformation of the previous $\mathrm{R}^{2}$ binding fragments (Figure 5), and so did the corresponding naphtalen-2-yl substituted fragment 27 $\left(I C_{50}(\mu \mathrm{M}) / \mathrm{LE}: 110 / 0.29\right)$. In the same manner the indol-5-yl substituted fragment $34\left(\mathrm{IC}_{50}\right.$ $(\mu \mathrm{M}) / \mathrm{LE}: 310 / 0.27)$ did show acceptable binding, yet no specific interaction except for the $\pi-$ stacking with Tyr211. In our previous paper, we investigated pyridin-4-yl and pyridin-3-yl substituted fragments (19), and both inhibited OXA-48 with the same potency $\left(\mathrm{IC}_{50}(\mu \mathrm{M}) / \mathrm{LE}\right.$ : 250/0.32). The pyridin-2-yl substituted fragments $35\left(I C_{50}(\mu M) / L E: 35 / 0.41\right)$ showed a $10-$ fold improvement in binding (Fig. $6 \mathrm{~A}$ and $\mathrm{B}$ ). In the crystal structure, two alternative conformations were observed (Fig. 6C). One conformation was the canonical with $\pi$-stacking of the pyridinyl ring with Tyr211 occupying the $R^{2}$ site (Fig. 6E), but in the other conformation the pyridinyl ring was orientated to the $\mathrm{R}^{1}$ site. The second conformation showed a hydrogen bond from the protonated $\mathrm{N}$ atom in the pyridine ring to the backbone carbonyl of Tyr117, which represents a unique interaction for the fragments in the library (Fig. 6D). Only the protonated pyridinyl-nitrogen would be able to form hydrogen bonds to 
the Tyr117 mainchain, which may explain the slower on/off-rates observed for fragment 35 in the SPR-experiments (Fig. 6B).

In the discussion above most fragments were identified as $\mathrm{R}^{2}$ binders with fragment $4 \mathrm{a}\left(\mathrm{I} \mathrm{C}_{50}\right.$ $(\mu \mathrm{M}) / \mathrm{LE}: 50 / 0.38)$ being the strongest binder among them. For $\mathrm{R}^{2}$ binders, the edge-to-face $\pi$ - $\pi$-stacking with Tyr211 appears to be an important interaction in accordance with previous analyses (23). Fragment 35 showed the best ligand efficiency $\left(I C_{50}(\mu M) / L E: ~ 35 / 0.42\right)$, but could not be classified as a $\mathrm{R}^{1}$ or $\mathrm{R}^{2}$ binder as both binding pockets showed useful interactions (Fig. 6C-E). Only two $R^{1}$ binders - fragments 21a and 26b - were identified, both showing hydrogen bonds with Arg214 as cause for the fragments orientation towards the $\mathrm{R}^{1}$ site.

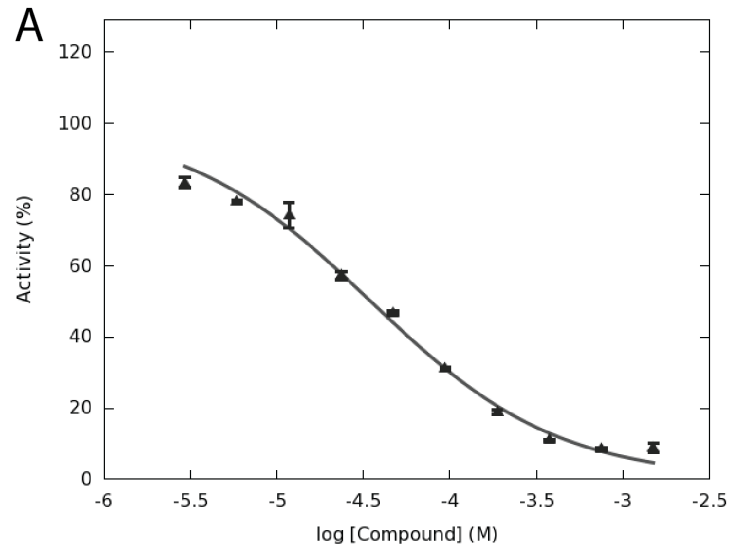

C

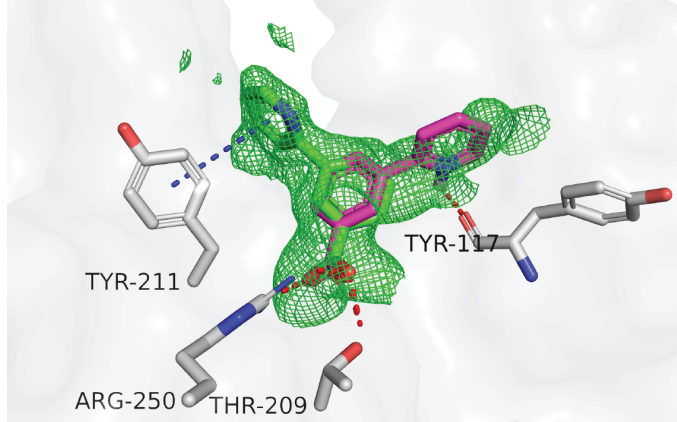

B

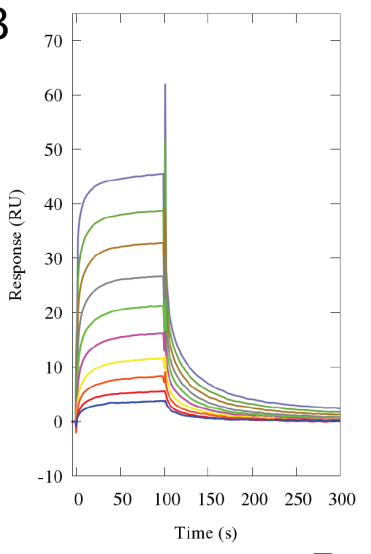

$\mathrm{E}$

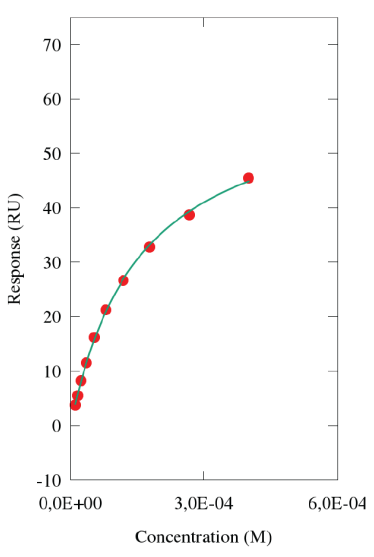

D

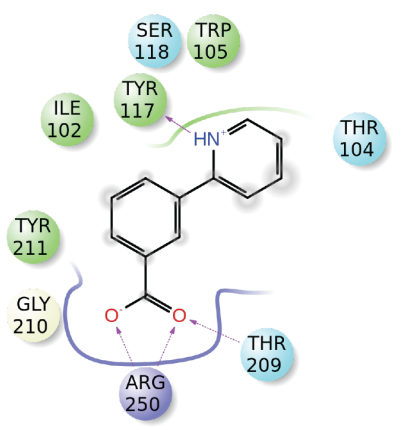

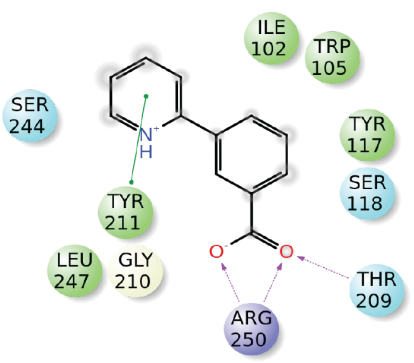

378

Figure 6: Compound 35 bound in the two alternate conformations. The $I C_{50}$-value $(A)$ was determined to be $35 \mu \mathrm{M}$, while the $K_{D}$ was found to be $159 \mu \mathrm{M}(B)$. The crystal structure of

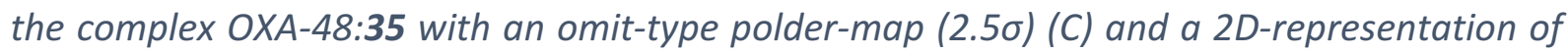
the protein:compound complex interactions. ( $D$ for green colored conformation, $E$ for magenta colored conformation).

\subsubsection{NMR studies}

In order to evaluate the fragment-enzyme binding in solution, a ${ }^{13} \mathrm{C}$ NMR experiment for OXA-48 was developed based on previous studies $(24,25)$. OXA enzymes can be selectively carbamylated with bicarbonate at an active site lysine to provide the corresponding carbamic acid $(24,26,27)$. For OXA-48 the carbamylated residue is Lys73, which is situated in the $\mathrm{R}^{1}$ site (Fig. 2B). By using ${ }^{13} \mathrm{C}$-labeled sodium bicarbonate $\left(\mathrm{NaH}^{13} \mathrm{CO}_{3}\right)$, a ${ }^{13} \mathrm{C}$ atom was 
introduced in the $\mathrm{R}^{1}$ site of OXA-48, which can be used as a reporter probe for fragment binding in ${ }^{13} \mathrm{C}$ NMR studies.

Fragments binding in the $R^{1}$ site were expected to change the local environment of the ${ }^{13} \mathrm{C}$ labelled Lys73, which results in a change of the ${ }^{13} \mathrm{C}$ chemical shift of $\mathrm{Lys}-\mathrm{NH}-{ }^{13} \mathrm{CO}_{2} \mathrm{H}$, while ligands binding in the $R^{2}$ site are further than $\sim 9 \AA$ away from the Lys 73 carbamic acid, and are therefore not expected to directly affect the ${ }^{13} \mathrm{C}$ chemical shift.

NMR experiments were performed by equilibrating OXA-48 with ${ }^{13} \mathrm{C}$-labeled sodium bicarbonate followed by the addition of inhibitor 2 and selected fragments 21a, 28 and $\mathbf{3 5}$ with known binding modes from $X$-ray analysis. The results are shown in Fig. 7 . The ${ }^{13} \mathrm{C} N \mathrm{NR}$ spectrum of OXA-48 after equilibration with $\mathrm{NaH}^{13} \mathrm{CO}_{3}$ showed the carbamate resonance at $163.95 \mathrm{ppm}$ as a broad signal (Fig. 7E), which is in good agreement with the reported chemical shift for carbamylated OXA-48 (28). In addition, two unassigned signals were observed at $164.04 \mathrm{ppm}$ similar to the results reported for carbamylation of OXA-58 (27). Here the authors speculated that the unassigned signal may be related to a second carbamylation site (27).

On addition of $\mathrm{R}^{1}$ binding fragment 21a and inhibitor 2 , the ${ }^{13} \mathrm{C}$ chemical shifts of the carbamate signal were consistently deshielded in both experiments $(\delta=164.25, \Delta \delta=0.28$ ppm, Fig. 7E and 7F). These findings support that the compounds bind competitively in the active site. Moreover, the observed chemical shift perturbation indicates that the compounds occupy the $R^{1}$ site as found in the crystal structures. The $R^{2}$ binding fragment $\mathbf{2 8}$ showed a similar deshielding of the carbamate signal though at a smaller amplitude $(\delta=$ $164.13, \Delta \delta=0.16 \mathrm{ppm}$, Fig. 7D) supporting that the fragment binds in the active site, while fragment 35, which was identified as $R^{1}$ or $R^{2}$ binder, only slightly affected the chemical shift $(\delta=164.00, \Delta \delta=0.04 \mathrm{ppm}$, Fig. 7C). The observed chemical shift perturbations for fragments $\mathbf{2 8}$ and $\mathbf{3 5}$ may indicate that fragment $\mathbf{2 8}$ has an effect on carbamylated Lys 73 , while fragment 35 do not interact with the $R^{1}$ site, which is not consistent with the $X$-ray structures. However, a more detailed study of the NMR conformations would be needed to be conclusive about the binding poses in solution.

The small amplitudes of the observed chemical shift perturbations indicated that the effect is not caused by direct hydrogen bonding of the carbamic carbonyl, for which a $\Delta \delta$ of several ppm would be expected, even for a $\mu \mathrm{M}$ binder (29). This was supported by the crystal structures of OXA-48 indicating that the Lys 73 carbamic acid was preoccupied in hydrogen bonding to Trp157 and was not affected by ligand binding. The observed consistent, but rather subtle, deshielding of the Lys 73 carbamic acid $(\delta=164.25, \Delta \delta=0.28$ ppm, Fig. $7 \mathrm{E}$ and 7F) for our $\mathrm{R}^{1}$ binding fragments can possibly be explained by an anisotropic magnetic deshielding by the edge of the aromatic rings of these fragments, which were positioned roughly $5 \AA$ away from the reporter carbon for $\mathrm{R}^{1}$ binding fragments. Moreover, amplitude of the chemical shift perturbation observed with $R^{1}$ binding fragments 21a and inhibitor 2 (Fig. 7E and 7F) were in line with the reported changes observed for OXA enzymes on coordination with inhibitors like $\beta$-hydroxyisopropylpenicillanates (24), cyclic boronates (25) and avibactam (28). 
A

B

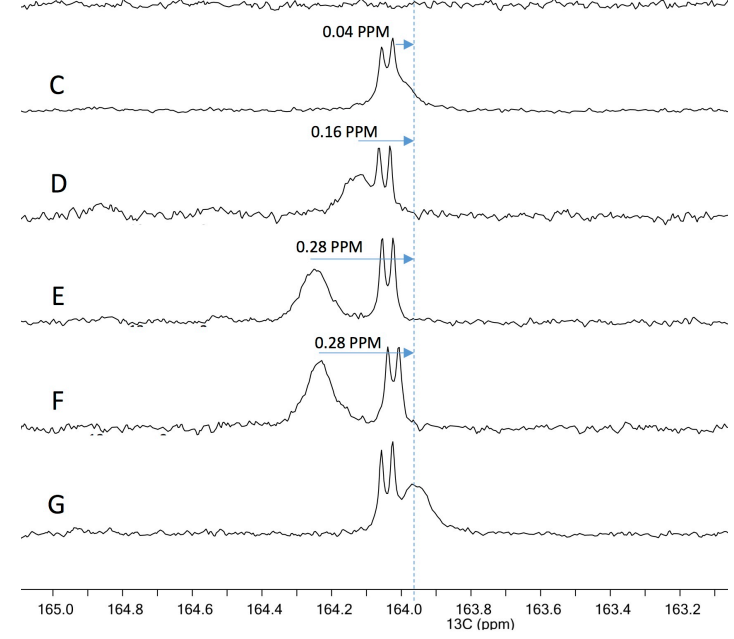

431

Figure 7: ${ }^{13} \mathrm{C} N \mathrm{NR}$ of the buffer alone including ${ }^{13} \mathrm{C}$ labeled bicarbonate $(A)$; OXA-48 without $433{ }^{13} \mathrm{C}$ labeled bicarbonate (B), OXA-48 with ${ }^{13} \mathrm{C}$ labeled bicarbonate and fragment 35 (C); OXA43448 with ${ }^{13} \mathrm{C}$ labeled bicarbonate and fragment $28(D)$; OXA-48 with ${ }^{13} \mathrm{C}$ labeled bicarbonate and fragment 21a (E); OXA-48 with ${ }^{13} \mathrm{C}$ labeled bicarbonate and 3,5-di(4-pyridinyl)benzoic acid 2 (F) and OXA-48 with ${ }^{13} \mathrm{C}$ labeled bicarbonate and no fragment (G). Two unassigned signals were observed at $164.1 \mathrm{ppm}$, and are believed to originate in a second carboxylated site of OXA-48. In an attempted to design more potent inhibitors from our fragments, the mono-substituted benzoic acids were evaluated for a merging approach (Fig. 8). By overlaying X-ray structures, promising combinations showing orthogonal binding poses were identified and some of the combined structures were prepared and evaluated with good results.

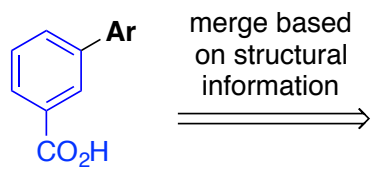<smiles>O=C(O)c1cc(Br)cc(Br)c1</smiles>

Ar = substituted phenyl or heterocyclic groups

445 Figure 8: Strategy for substitution of the $A r^{1}$ and $A r^{2}$ groups in the focused fragment library of 3-substituted benzoic acids analogues.

An overlay of fragment $\mathbf{2 1 a}$ as well as $\mathbf{2 6}$ bith several $\mathrm{R}^{2}$ binders identified the combinations of fragments $\mathbf{2 1 a} / \mathbf{2 8}, \mathbf{2 1 a} / \mathbf{1}$ and $\mathbf{2 6 b} / \mathbf{3 5}$ as interesting partners (Fig. 9). The combination $\mathbf{2 1 a} / \mathbf{1}$ and $\mathbf{2 1 a} / \mathbf{2 8}$ were synthetically feasible and gave compounds $\mathbf{3 9}$ and $\mathbf{4 0}$ (Scheme 2), respectively. In addition, the symmetrical 3,5-disubstituted benzoic acids 36-38 representing the symmetrical combinations of fragments $\mathbf{2 1 a}, \mathbf{2 1} \mathbf{b}$ and $\mathbf{2 8}$ were included in this study (Scheme 1). 

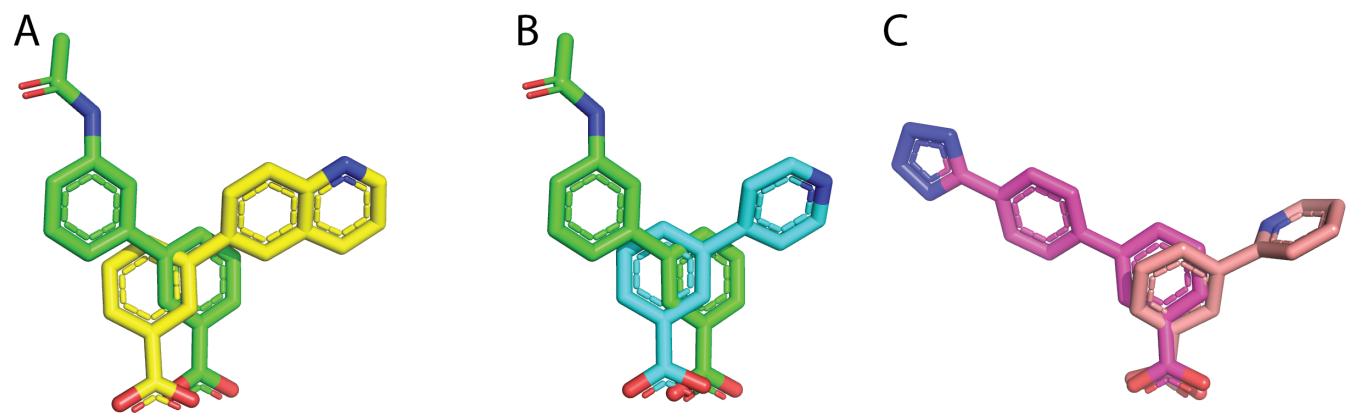

454 Figure 9: Superimpositions of the binding poses observed for 21a/28 (A), 21a/1 (B, 1: PDB-

455 ID:5dva) and 26b/35 (C) showing some of the possible combinations for 3,5-disubstituted 456 benzoic acids.

457 The 3,5-disubstituted compounds 36-40 were evaluated for their inhibitory activity against 458 OXA-48 as measured by their $\mathrm{IC}_{50}, \mathrm{~K}_{d}$ and $\mathrm{LE}$ and complex structures with OXA-48 and 459 compounds 36, $\mathbf{3 8}$ and $\mathbf{4 0}$ were obtained (Table 2). The merged compounds $\mathbf{3 7}, \mathbf{3 8}$ and $\mathbf{3 9}$ $460\left(\mathrm{IC}_{50}(\mu \mathrm{M}) / \mathrm{LE}: 110 / 0.19,48 / 0.21,100 / 0.22\right)$ failed to adequately maintain the binding 461 interactions as the $\mathrm{IC}_{50}$ values were at a similar level as the corresponding mono-substituted 462 fragments 28, 1 and 21a $\left(I_{50}(\mu \mathrm{M}) / L E:\right.$ 240/0.33, 250/0.32 and 35/0.33). When comparing 463 the $I_{50}$ values of compounds 36,37 and $40\left(I_{50}(\mu M) / L E: 2.9 / 0.27,48 / 0.21\right.$ and 2.9/0.27) 464 with the corresponding fragments 21a, 21b and $28\left(I_{50}(\mu \mathrm{M}) / L E: 35 / 0.33,450 / 0.26\right.$, 465 240/0.3), a 10-fold decrease of the $I C_{50}$ value was observed. Nevertheless, the improved 466 binding was associated with a decrease in LE showing that the fragment-enzyme interactions 467 are less efficient with the merged compounds. The reduction in LE probably relates to the rigid structure of the merged compounds allowing for little conformational freedom. Overall, the strongest inhibitors in this study are compounds $\mathbf{3 6}$ and $\mathbf{4 0}$ with $\mathrm{IC}_{50}$ values of $2.9 \mu \mathrm{M}$ and LE of 0.27 .

Table 2. Inhibitor activities of 3,5-disubstituted benzoic acids analogues against OXA-48 (IC 50 , $472 K_{D}$ and $\left.L E\right)$.

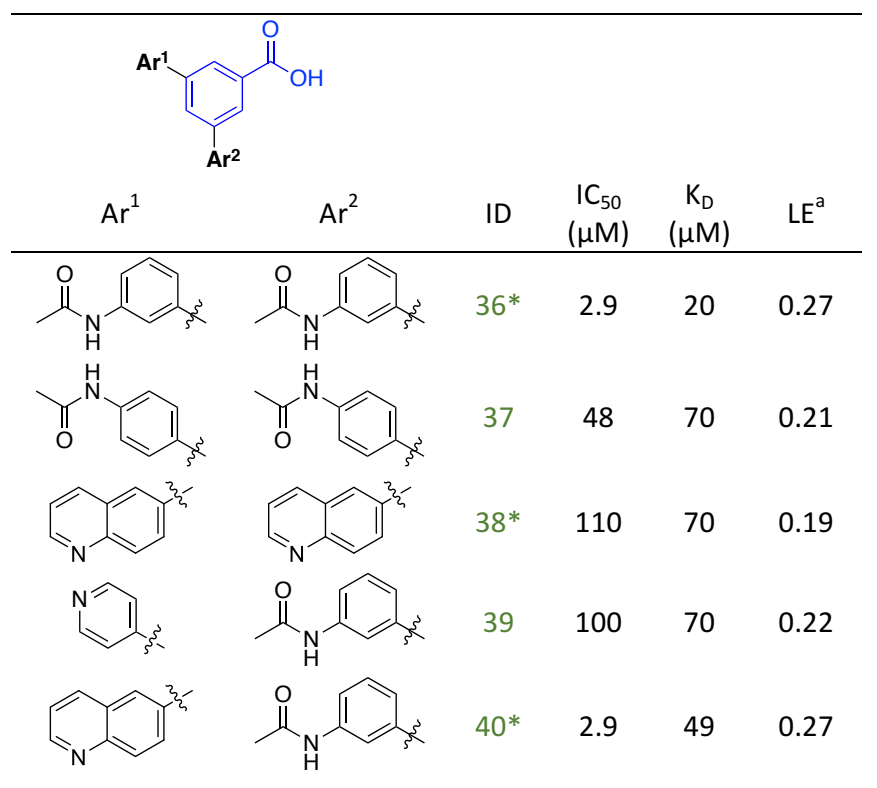


*X-ray structure of fragment-enzyme complex available. ${ }^{a} \mathrm{LE}=-\log _{10} \mathrm{IC}_{50} /$ HeavyAtomCount

A

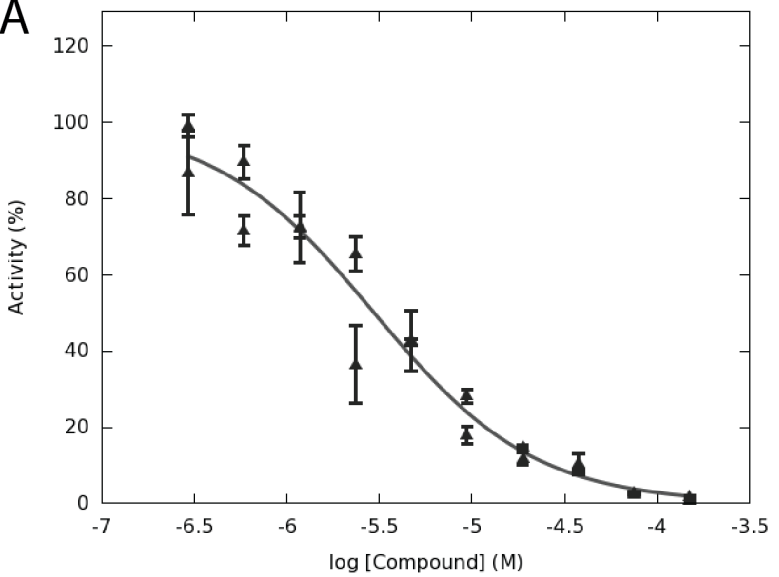

C

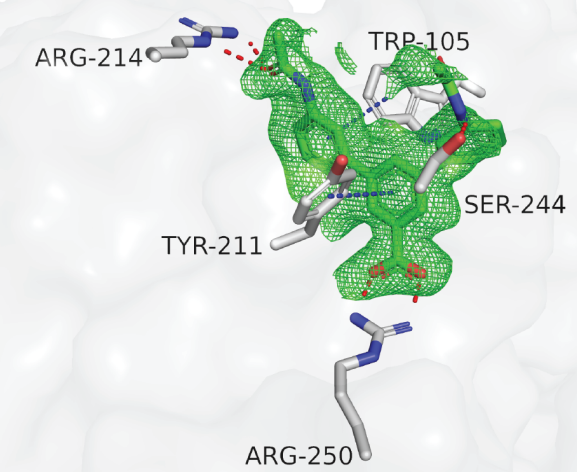

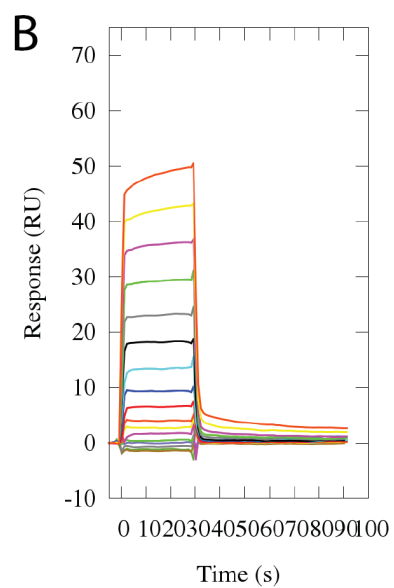

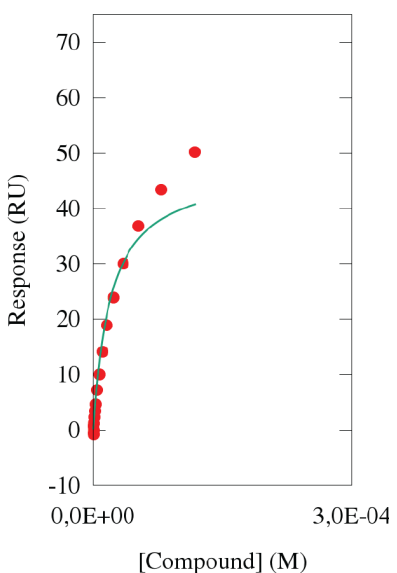

$\mathrm{D}$

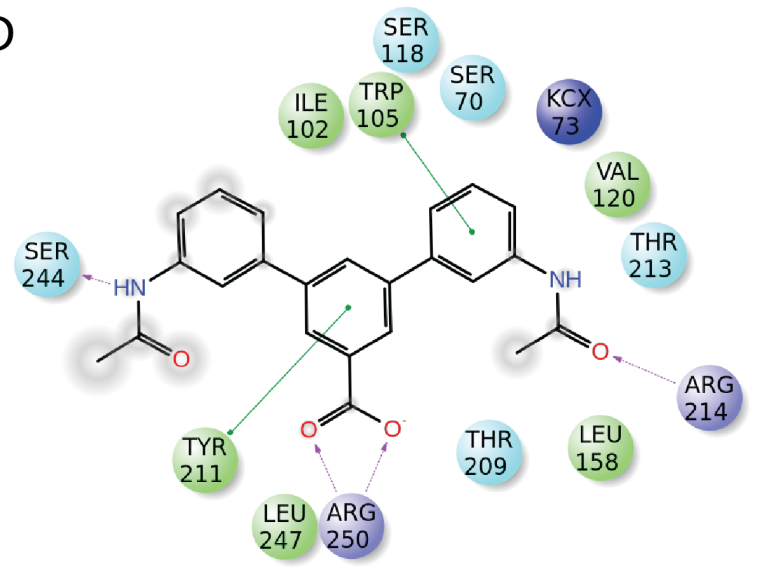

474

475

476

477

478

479

480

481

482

483

484

485

486

487

488

489

490

491

492

Figure 10: Compound 36 maintained the interaction with Arg214 as we observed for the 3substituted benzoic acid derivate. The $I C_{50}$-value $(A)$ was determined to be $2.9 \mu \mathrm{M}$, while the $K_{D}$ was found to be $30 \mu \mathrm{M}(B)$. For the higher concentrations of compound 36 some unspecific binding was observed. The crystal structure of the complex OXA-48:36 with an omit-type polder-map (2.5o) (C) and its 2D-representation (D) shows one of the acetamide-groups interacted with the guanidine group of Arg214, while the other group was solvent exposed.

The structural analysis of the OXA-48 complexes with 36, 38 and $\mathbf{4 0}$ showed that the interaction of the carboxylic acid with Arg214 is maintained. For compound 36, a near perfect overlay was obtained with the complex structure of fragment 21a showing that all interactions seen with the fragments were preserved in the larger compound (Fig. 10). The second 3- $N$-acetamidophenyl group forms a not previously observed hydrogen bond with Ser244. In the SPR sensorgrams some concentration dependent aggregation was observed. (30)

Interestingly, the conformation of compound 38 in complex with OXA-48 was changed compared with the mono-substituted fragment 28. In the OXA-48:38 complex, one quinolinyl group bound in the $\mathrm{R}^{1}$ site similar to fragment 21a. The other quinolinyl group positions itself in a conformation similar to the alternative conformation observed with fragment 35 (Fig. 6). No specific interactions were observed, but this conformation shielded 
the hydrophobic quinoline ring from solvent exposure by burying the compound deep in the hydrophobic cleft.

The complex structure of the unsymmetrical compound $\mathbf{4 0}$ (Fig. 11) that was composed of the quinoline ring of fragment $\mathbf{2 8}$ and the $3-N$-acetamidophenyl substituent of fragment $\mathbf{1 3 a}$ shared the key interactions of both mono-substituted fragments validating our approach, with an $\mathrm{IC}_{50}$ of $2.9 \mu \mathrm{M}$.

\section{Conclusion}

A targeted fragment library consisting of 49 diversely 3-substituted benzoic acid derivatives was prepared and biochemically analysed for their inhibitory activity against OXA-48. Enzyme-fragment complexes for crystallographic studies were obtained for 33 fragments. By systematically changing the substituent-groups of the benzoic acid derivatives we were able to identify inhibitory fragments with $\mathrm{IC}_{50}<40 \mu \mathrm{M}(\mathbf{2 1 a}, \mathbf{2 6 \mathbf { b }}, \mathbf{3 5})$. Based on the structural information, fragments could be classified according to their preferred binding pocket. Most fragments were orientated towards the $R^{2}$ site induced by a $\pi$ - $\pi$-stacking with Tyr221. Unfortunately, no further interactions in the $\mathrm{R}^{2}$ site could be identified from our library. The strongest binding fragments $\mathbf{2 1 a}$ and $\mathbf{2 6} \mathbf{b}$ were binding in the $\mathrm{R}^{1}$ site due to a hydrogen bond to Arg214 and for fragment $\mathbf{3 5}$ a hydrogen bond to the carbonyl backbone of Tyr117 was observed. By overlaying the complex crystal structures of fragments 1, 21a, 26b, 28 and 35, the design of five new 3,5-disubstituted inhibitors evolved. The strongest 3,5-disubstituted inhibitors $\mathbf{3 6}$ and $\mathbf{4 0}$ showed $\mathrm{IC}_{50}$ values as low as $2.9 \mu \mathrm{M}$, thus have improved inhibitory potential. The complex crystal structures of $\mathbf{3 6}$ and $\mathbf{4 0}$ revealed that the interactions of the individual fragments were mainly retained in the merged structures. In addition, for inhibitor 36 a previously not observed hydrogen bond from the 3- $N$-acetamidophenyl group in the $\mathrm{R}^{2}$ site to Ser244 was found, which is interesting as we otherwise found few interactions in this region. Future work will focus on the evaluation of fragments with increased flexibility e.g. by introducing a $\mathrm{CH}_{2}$ or heteroatom linker bridging the aromatic ring systems to further explore the active site. 

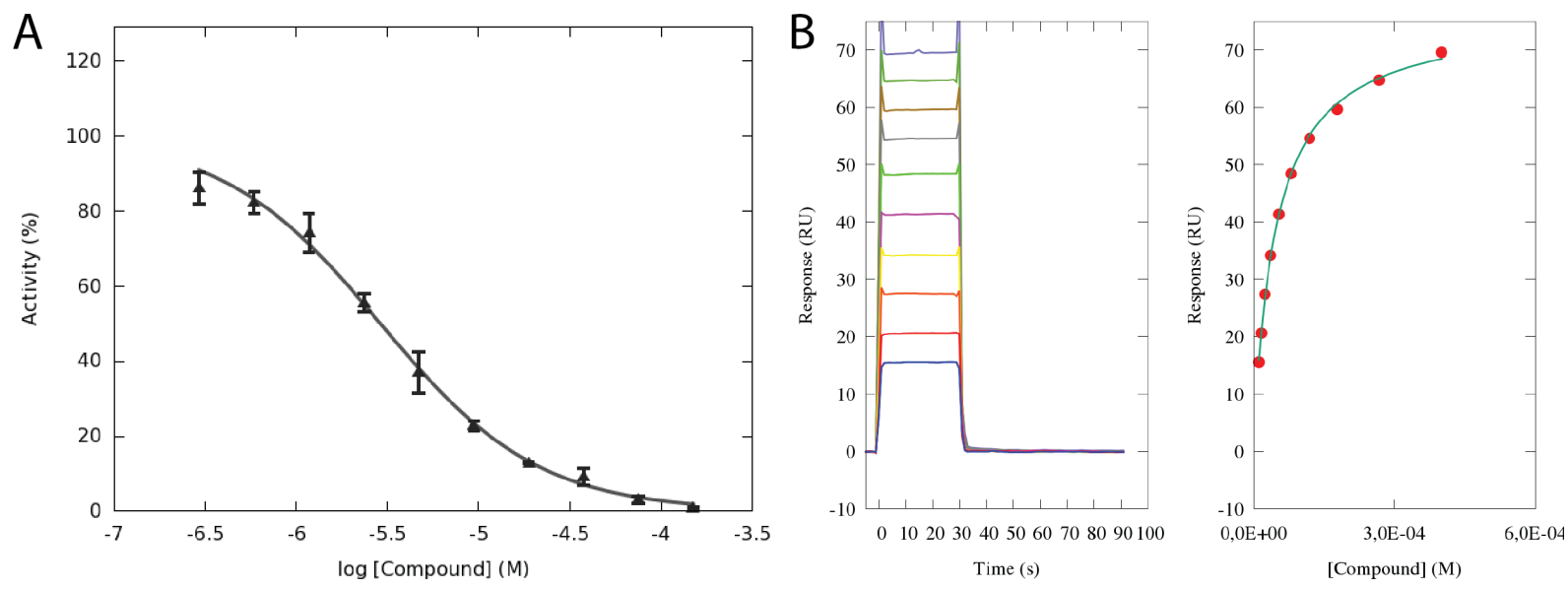

C

$\mathrm{D}$
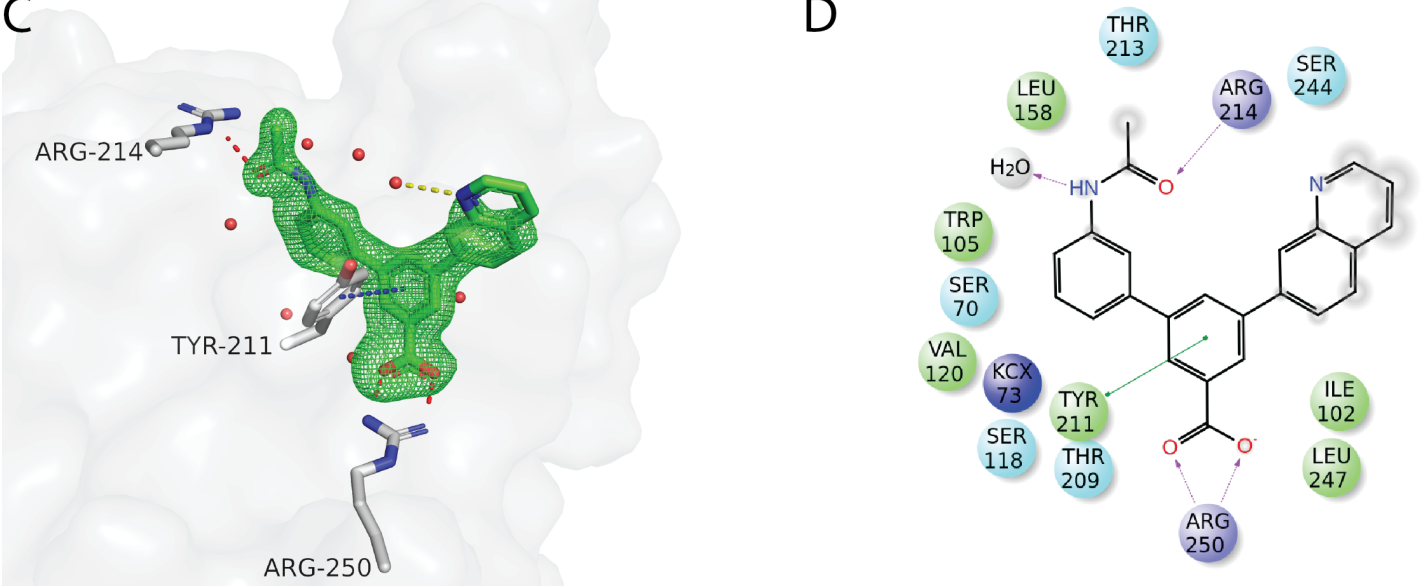

Figure 11: Compound 40 maintained the interaction with Arg214 as we observed for the 3substituted benzoic acid derivate. The $I C_{50}$-value $(A)$ was determined to be $2.9 \mu \mathrm{M}$, while the $K_{D}$ was found to be $49 \mu \mathrm{M}(B)$. The crystal structure of the complex OXA-48:40 with an omittype polder-map (2.50) (C) and its 2D-representation (D) shows that the acetamide-group interacted with the guanidine group of Arg214, while the quinoline-ring was partially solvent exposed.

\section{Experimental}

$528 \quad 4.1 \quad$ Synthesis

\subsubsection{Synthesis of 3-substituted benzoic acids (complete data for all procedures and compounds is} found in the Supporting Information)

\subsubsection{General procedure A - Aqueous conditions:}

532 The halo aryl (1.0 equiv) was dissolved in a mixture of water:dioxane (1:1). The boronic acid or ester (1.5 equiv) and potassium phosphate (5.0 equiv) were added. The solution was degassed by vacuum/Argon cycles (10 times) before addition of $\mathrm{PdCl}_{2}\left(\mathrm{PPh}_{3}\right)_{2}(10 \mathrm{~mol} \%$ ) and further degassed (5 times). The resulting mixture was stirred at $95{ }^{\circ} \mathrm{C}$ under argon atmosphere for 16-20 hours. The reaction mixture was filtered through Celite and diluted with water (approx. $30 \mathrm{~mL}$ ) before washing with chloroform $(3 \times 30 \mathrm{~mL})$. If not stated otherwise, the aqueous phase was concentrated under reduced pressure and applied to a 539 C18 precolumn before purification on a $10 \mathrm{~g}$ or $60 \mathrm{~g}$ C18 column with a gradient of acetonitrile in water (10-100\%) to yield the desired product. 
542 The halo aryl (1.0 equiv) was dissolved in anhydrous THF. The aryl boronic acid or aryl 543 boronic ester (1.5 equiv) and inorganic base (5.0 equiv) were added. The solution was 544 degassed by vacuum/Argon cycles (10 times), before addition of a palladium catalyst (10 mol\%) and further degassed (5 times). The resulting mixture was stirred at $75-90{ }^{\circ} \mathrm{C}$ under an inert atmosphere for 16-20 hours. The reaction mixture was filtered through Celite and diluted with water (approx. $30 \mathrm{~mL}$ ) before washing with ethyl acetate $(3 \times 30 \mathrm{~mL}$ ). If not stated otherwise, the aqueous phase was concentrated under reduced pressure and applied to a C18 precolumn before purification on a $10 \mathrm{~g}$ or $60 \mathrm{~g} \mathrm{C} 18$ column with a gradient of acetonitrile in water (10-80\%) to yield the desired molecule.

\subsubsection{Screening of catalysts (for results see Table SI1)}

\subsubsection{General procedure:}

3-Bromo-5-iodobenzoic acid (0.03-0.06 mmol, 1.0 equiv.) was dissolved in the indicated solvent (0.5-1 mL/0.01 mmol substrate). The boronic acid or ester (1.5 equiv.) and base (5.0 equiv.) were added. The solution was degassed by vacuum/Ar cycles (10 times) before addition of the palladium catalyst and further degassed (5 times). The resulting mixture was stirred at the indicated temperature under an inert atmosphere for the indicated reaction time. The crude reaction mixture was analysed by HRMS to determine the ratio of int-39 : disubstituted 38 : starting material. The reaction mixture was filtered through Celite bed and diluted with water (approx. $30 \mathrm{~mL}$ ) before washing with chloroform ( $3 \times 30 \mathrm{~mL}$ ). The aqueous phase was concentrated under reduced pressure and applied to a C18 precolumn before purification on a $60 \mathrm{~g}$ C18 column with a gradient of acetonitrile in water (0-5\% over $15 \mathrm{~min}$ ) to yield the product.

\subsubsection{Synthesis of symmetrical 3,5-disubstituted benzoic acid derivatives}

\subsubsection{3,5-Di(3-acetamidophenyl)benzoic acid 36:}

3-Bromo-5-iodobenzoic acid $(0.30 \mathrm{mmol}, 100 \mathrm{mg}, 1.0$ equiv), 3-acetamidophenylboronic acid ( $0.45 \mathrm{mmol}, 816 \mathrm{mg}, 1.5$ equiv), potassium phosphate $(1.5 \mathrm{mmol}, 324 \mathrm{mg}, 5.0$ equiv) were dissolved in a mixture of water/dioxane (1:1). The solution was degassed by vacuum/ $\mathrm{Ar}$ cycles (10 times) before addition of $\mathrm{Pd}_{2}(\mathrm{dba})_{3} \cdot \mathrm{CHCl}_{3}(15 \mathrm{mg}, 5 \mathrm{~mol} \%)$, and XPhos (7.2 $\mathrm{mg}, 5$ mol\%) and further degassed ( 5 times). The resulting mixture was stirred at $60{ }^{\circ} \mathrm{C}$ for $20-24$ hours. The reaction mixture was filtered through Celite bed and diluted with water (approx. $30 \mathrm{~mL}$ ) before washing with chloroform $(3 \times 30 \mathrm{~mL})$. The aqueous phase was concentrated under reduced pressure and applied to a C18 precolumn before purification on a $60 \mathrm{~g} \mathrm{C18}$ column with a gradient of acetonitrile in water $(0-5 \%$ over $15 \mathrm{~min})$ to provide $\mathbf{3 6}(60 \mathrm{mg}$, $54 \%$ ) as white powder. ${ }^{1} \mathrm{H} \mathrm{NMR}\left(400 \mathrm{MHz}\right.$, methanol- $\left.d_{4}\right) \delta 8.21(\mathrm{~s}, 2 \mathrm{H}), 7.90(\mathrm{t}, J=1.7 \mathrm{~Hz}, 1 \mathrm{H})$, $7.81(\mathrm{t}, J=1.7 \mathrm{~Hz}, 2 \mathrm{H}), 7.68(\mathrm{~d}, J=8 \mathrm{~Hz}, 2 \mathrm{H}), 7.43(\mathrm{~s}, 1 \mathrm{H}), 7.49-7.46(\mathrm{~m}, 2 \mathrm{H}), 7.43-7.39(\mathrm{~m}$, $2 \mathrm{H}), 2.16(\mathrm{~s}, 6 \mathrm{H}) .{ }^{13} \mathrm{C} \mathrm{NMR}\left(101 \mathrm{MHz}\right.$, methanol- $\left.d_{4}\right) \delta 175.0,171.8,142.9,142.3,140.5,132.2$, 130.4, 128.2, 128.1, 123.9, 120.3, 119.7, 24.0. HRMS (ESI): Calcd. for $\mathrm{C}_{23} \mathrm{H}_{19} \mathrm{~N}_{2} \mathrm{O}_{4}[\mathrm{M}-\mathrm{H}]^{-}$ 387.1350; found 387.1342. UPLC: purity $=97.5 \%$ 


\subsubsection{3,5-di(4-acetamidophenyl)benzoic acid 37:}

3,5-Dibromobenzoic acid (1.01 mmol, $300 \mathrm{mg}, 1.0$ equiv), 3-acetamidophenylboronic acid (0.81 mmol, $178 \mathrm{mg}, 0.75$ equiv), potassium phosphate ( $3.76 \mathrm{mmol}, 0.80 \mathrm{~g}, 3.5$ equiv) and $\mathrm{PdCl}_{2}\left(\mathrm{PPh}_{3}\right)_{2}(0.11 \mathrm{mmol}, 77 \mathrm{mg}, 10 \mathrm{~mol} \%)$ were stirred in a mixture of water/dioxane (1:1) for 24 hours at $95{ }^{\circ} \mathrm{C}$ under argon atmosphere. The crude reaction mixture was filtered through Celite and diluted with water (approx. $30 \mathrm{~mL}$ ) before washing with chloroform ( $3 \mathrm{x}$ $30 \mathrm{~mL}$ ). The aqueous phase was concentrated under reduced pressure and applied to a C18 precolumn before purification on a $60 \mathrm{~g} \mathrm{C18}$ column with a gradient of acetonitrile in water (0-100\% over 12 minutes). The fractions were analysed by MS and fractions containing 37 were combined. The product was purified by reverse-phase automated flash chromatography before being subjected to purification by HPLC, to yield $\mathbf{3 7}(0.09 \mathrm{mmol}, 34$ $\mathrm{mg}, 11 \%)$ as a white solid. ${ }^{1} \mathrm{H}$ NMR $\left(400 \mathrm{MHz}\right.$, methanol- $\left.d_{4}\right) \delta 8.24(\mathrm{~s}, 2 \mathrm{H}), 7.98(\mathrm{~d}, J=7.8 \mathrm{~Hz}$, $2 \mathrm{H}), 7.85(\mathrm{~d}, J=7.9 \mathrm{~Hz}, 2 \mathrm{H}), 7.68-7.66(\mathrm{~m}, 2 \mathrm{H}), 7.63-7.60(\mathrm{~m}, 2 \mathrm{H}), 7.57-7.53(\mathrm{~m}, 1 \mathrm{H}), 2.16(\mathrm{~s}$, $6 \mathrm{H}) .{ }^{13} \mathrm{C}$ NMR $\left(101 \mathrm{MHz}\right.$, methanol- $\left.d_{4}\right) \delta 175.2,171.7,142.0,140.2,139.4,137.9,131.7$, $128.4,128.2,127.6,127.4,123.3,121.4,116.2$, 23.9. HRMS (ESI): Calcd. for $\mathrm{C}_{23} \mathrm{H}_{19} \mathrm{~N}_{2} \mathrm{O}_{4}$ [MH] 387.1350 ; found 387.1340. UPLC: purity $>99.5 \%$

\subsubsection{3,5-diquinolin-6-ylbenzoic acid 38:}

3,5-Dibromobenzoic acid ( $0.11 \mathrm{mmol}, 33 \mathrm{mg}, 1.0$ equiv), 6-quinolinylboronic acid pinacol ester ( $0.23 \mathrm{mmol}, 60 \mathrm{mg}, 2.0$ equiv), potassium phosphate $(0.58 \mathrm{mmol}, 125 \mathrm{mg}, 5.0$ equiv) were dissolved in tert-butanol. The solution was degassed by vacuum/Ar cycles (10 times) before addition of XPhos-Pd G2 ( $5 \mathrm{~mol} \%, 5 \mathrm{mg}$ ) and further degassed ( 5 times). The resulting mixture was stirred at $60{ }^{\circ} \mathrm{C}$ for $20-24$ hours. The reaction mixture was filtered through Celite bed and diluted with water (approx. $30 \mathrm{~mL}$ ) before washing with chloroform $(3 \times 30$ $\mathrm{mL}$ ). The aqueous phase was concentrated under reduced pressure and applied to a C18 precolumn before purification by $\mathrm{C} 18 \mathrm{RP}$ flash chromatography with a gradient of acetonitrile in water (0-5\% over $15 \mathrm{~min})$ to yield $38(0.08 \mathrm{mmol}, 29 \mathrm{mg}, 65 \%)$ as white powder. ${ }^{1} \mathrm{H}$ NMR $\left(400 \mathrm{MHz}\right.$, methanol- $\left.d_{4}\right) \delta 8.87-8.86(\mathrm{~m}, 2 \mathrm{H}), 8.52(\mathrm{~s}, 1 \mathrm{H}), 8.50(\mathrm{~s}, 1 \mathrm{H}), 8.46$ $(\mathrm{m}, 2 \mathrm{H}), 8.38(\mathrm{~m}, 2 \mathrm{H}), 8.29-8.26(\mathrm{~m}, 3 \mathrm{H}), 8.18(\mathrm{~s}, 1 \mathrm{H}), 8.16(\mathrm{~s}, 1 \mathrm{H}), 7.61-7.58(\mathrm{dd}, J=8.3,4.2$ $\mathrm{Hz}, 2 \mathrm{H}) .{ }^{13} \mathrm{C}$ NMR $\left(101 \mathrm{MHz}\right.$, methanol- $\left.d_{4}\right) \delta 174.4,151.1,148.0,141.5,140.5,138.6,130.6$, 130.1, 129.5, 128.7, 126.9, 122.8. HRMS (ESI): Calcd. for $\mathrm{C}_{25} \mathrm{H}_{15} \mathrm{~N}_{2} \mathrm{O}_{2}[\mathrm{M}-\mathrm{H}]^{-}$375.1139; found 375.1133. UPLC: purity $=99.1 \%$

\subsubsection{Synthesis of unsymmetrical 3,5-disubstituted benzoic acid derivatives}

4.1.4.1 3-(3'-Acetamidophenyl)-5-pyridin-4-ylbenzoic acid 39: attempted synthesis from 3,5dibromobenzoic acid

3,5-Dibromobenzoic acid (1.01 mmol, $300 \mathrm{mg}, 1.0$ equiv), 3-acetamidophenylboronic acid ( $0.81 \mathrm{mmol}, 178 \mathrm{mg}, 0.75$ equiv), potassium phosphate $(3.76 \mathrm{mmol}, 0.80 \mathrm{~g}, 3.5$ equiv) and $\mathrm{PdCl}_{2}\left(\mathrm{PPh}_{3}\right)_{2}(0.11 \mathrm{mmol}, 77 \mathrm{mg}, 10 \mathrm{~mol} \%)$ were stirred in a mixture of water/dioxane (1:1) for 24 hours at $95{ }^{\circ} \mathrm{C}$ under argon atmosphere. The crude reaction mixture was filtered through Celite and diluted with water (approx. $30 \mathrm{~mL}$ ) before washing with chloroform $(3 \mathrm{x}$ $30 \mathrm{~mL}$ ). The aqueous phase was concentrated under reduced pressure and applied to a C18 precolumn before purification by C18 RP flash chromatography with a gradient of acetonitrile in water (10-100\% over 12 minutes). The fractions were analysed by MS and 
fractions containing int-39 were combined and reacted with pyridin-4-ylboronic acid (0.97 mmol, $119 \mathrm{mg}, 1.2$ equiv), potassium phosphate (4.05 mmol, $0.86 \mathrm{~g}, 5.0$ equiv) and $\mathrm{PdCl}_{2}\left(\mathrm{PPh}_{3}\right)_{2}(0.08 \mathrm{mmol}, 56 \mathrm{mg}, 10 \mathrm{~mol} \%)$. The product was purified by reverse-phase automated flash chromatography before being subjected to purification by HPLC, to yield 39 (0.12 mmol, $39 \mathrm{mg}, 15 \%)$ as a white solid. ${ }^{1} \mathrm{H}$ NMR (400 MHz, methanol- $\left.d_{4}\right) \delta 8.22(\mathrm{~s}, 1 \mathrm{H})$, $7.92(\mathrm{~d}, J=7.6 \mathrm{~Hz}, 1 \mathrm{H}), 7.76(\mathrm{~s}, 2 \mathrm{H}), 7.68-7.60(\mathrm{~m}, 3 \mathrm{H}), 7.46-7.33(\mathrm{~m}, 4 \mathrm{H}), 2.14(\mathrm{~s}, 3 \mathrm{H}) .{ }^{13} \mathrm{C}$ NMR $\left(101 \mathrm{MHz}\right.$, methanol- $\left.d_{4}\right) \delta 175.3,171.7,143.0,141.5,140.4,139.8,130.3,129.7,129.3$, $129.3,128.9,123.7,120.1,119.6,23.9$. UPLC: purity $=97.9 \%$

\subsubsection{3-Bromo-5-(quinolin-6-yl) benzoic acid int-40:}

3-Bromo-5-iodobenzoic acid $(0.15 \mathrm{mmol}, 50 \mathrm{mg}, 1.0$ equiv), 6-quinolinylboronic acid pinacol ester $(0.22 \mathrm{mmol}, 58 \mathrm{mg}, 1.5$ equiv) and potassium phosphate $(0.76 \mathrm{mmol}, 162 \mathrm{mg}, 5.0$ equiv) were dissolved in a mixture of water/dioxane (1:1). The solution was degassed by vacuum/Ar cycles (10 times) before addition of $\mathrm{Pd}_{2}(\mathrm{dba})_{3} \cdot \mathrm{CHCl}_{3}(5 \mathrm{~mol} \%, 7.5 \mathrm{mg})$, and SPhos (5 mol\%, $3.1 \mathrm{mg}$ ) and further degassed (5 times). The resulting mixture was stirred at $60{ }^{\circ} \mathrm{C}$ for 20-24 hours. The reaction mixture was filtered through a Celite bed and diluted with water (approx. $30 \mathrm{~mL}$ ) before washing with chloroform $(3 \times 30 \mathrm{~mL})$. The aqueous phase was concentrated under reduced pressure and applied to a $\mathrm{C} 18$ precolumn before purification on a $60 \mathrm{~g} \mathrm{C18} \mathrm{column} \mathrm{with} \mathrm{a} \mathrm{gradient} \mathrm{of} \mathrm{acetonitrile} \mathrm{in} \mathrm{water} \mathrm{(0-5 \%} \mathrm{over} 20 \mathrm{~min}$ ). Product int$40(0.07 \mathrm{mmol}, 23 \mathrm{mg}, 45 \%)$ was obtained as a white powder. ${ }^{1} \mathrm{H} \mathrm{NMR}(400 \mathrm{MHz}$, methanol$\left.d_{4}\right) \delta 8.92-8.91(\mathrm{~m}, 1 \mathrm{H}), 8.49-8.46(\mathrm{~m}, 1 \mathrm{H}), 8.35(\mathrm{~s}, 1 \mathrm{H}), 8.28(\mathrm{~s}, 2 \mathrm{H}), 8.10(\mathrm{~s}, 2 \mathrm{H}), 8.02-8.01(\mathrm{~m}$, $1 \mathrm{H}), 7.97-7.96(\mathrm{~m}, 1 \mathrm{H}), 7.59-7.56(\mathrm{dd}, J=8.3,4.2 \mathrm{~Hz}, 1 \mathrm{H}) .{ }^{13} \mathrm{C}$ NMR $\left(101 \mathrm{MHz}, \mathrm{DMSO}-d_{6}\right) \delta$ 166.6, 150.8, 147.2, 143.6, 140.6, 136.8, 136.5, 131.7, 131.1, 129.6, 128.5, 128.2, 127.4, 126.5, 125.8, 121.9, 121.7; HRMS (ESI): Calcd. for $\mathrm{C}_{16} \mathrm{H}_{9}{ }^{79} \mathrm{BrNO}_{2}[\mathrm{M}-\mathrm{H}]^{-}$325.9822; found 325.9822 .

\subsubsection{3-(3'-Acetamidophenyl)-5-quinolin-6-ylbenzoic acid 40:}

3-Bromo-5-(quinolin-6-yl) benzoic acid int-40 (0.039 mmol, $13 \mathrm{mg}, 1.0$ equiv), 3acetamidophenylboronic acid $(0.55 \mathrm{mmol}, 10 \mathrm{mg}, 1.5$ equiv) and potassium phosphate $(0.20$ mmol, $0.42 \mathrm{~g}, 5.0$ equiv) were dissolved in tert-butanol. The solution was degassed by vacuum/Ar cycles (10 times) before addition of Xphos-Pd G2 (5 mol\%, $1.5 \mathrm{mg}$ ) and further degassed ( 5 times). The resulting mixture was stirred at $60{ }^{\circ} \mathrm{C}$ for $20-24$ hours. The reaction mixture was filtered through Celite bed and diluted with water (approx. $30 \mathrm{~mL}$ ) before washing with chloroform $(3 \times 30 \mathrm{~mL})$. The aqueous phase was concentrated under reduced pressure and applied to a C18 precolumn before purification on a $60 \mathrm{~g} \mathrm{C18}$ column with a gradient of acetonitrile in water (0-5\% over $20 \mathrm{~min}$ ). Product 40 (0.023 mmol, $9 \mathrm{mg}, 90 \%)$ was obtained as white powder. ${ }^{1} \mathrm{H}$ NMR $\left(400 \mathrm{MHz}\right.$, methanol- $\left.d_{4}\right) \delta 8.87-8.83(\mathrm{~m}, 1 \mathrm{H}), 8.56-$ $8.45(\mathrm{~m}, 1 \mathrm{H}), 8.41-8.39(\mathrm{~m}, 1 \mathrm{H}), 8.35-8.20(\mathrm{~m}, 3 \mathrm{H}), 8.18-8.11(\mathrm{~m}, 1 \mathrm{H}), 8.08(\mathrm{t}, J=1.8 \mathrm{~Hz}, 1 \mathrm{H})$, 7.87-7.86 (m, $1 \mathrm{H}), 7.72-7.68(\mathrm{~m}, 1 \mathrm{H}), 7.62-7.56(\mathrm{~m}, 1 \mathrm{H}), 7.56-7.49(\mathrm{~m}, 1 \mathrm{H}), 7.46-7.42(\mathrm{~m}, 1 \mathrm{H})$, 2.17 (s, 3H). ${ }^{13} \mathrm{C}$ NMR $\left(101 \mathrm{MHz}, \mathrm{DMSO}-d_{6}\right) \delta 174.7,171.8,151.2,148.2,142.8,142.5,141.4$, $140.8,140.7,140.5,138.8,130.8,130.4,130.3,129.7,128.6,128.5,128.5,127.0,123.9$, 123.0, 120.3, 119.7, 23.9. HRMS (ESI): Calcd. for $\mathrm{C}_{24} \mathrm{H}_{18} \mathrm{~N}_{2} \mathrm{O}_{3}[\mathrm{M}-\mathrm{H}]^{-}$381.1245; found 381.1243.UPLC: purity $=96.4 \%$ 
664 For the biochemical assay OXA-48 was expressed with the native signal-peptide and purified from the periplasm as described earlier.(31) For surface plasmon resonance assays, nuclear magnetic resonance and crystallization a His-tagged construct was used.(19)

All experiments were performed using a Spectramax $\mathrm{M} 2 \mathrm{e}$ at $25{ }^{\circ} \mathrm{C}$ in $100 \mathrm{mM}$ sodium phosphate ( $\mathrm{pH}$ 7.0) supplemented with $50 \mathrm{mM} \mathrm{NaHCO}$ and $0.2 \mathrm{mg} / \mathrm{ml}$ bovine serum albumin (BSA). Velocities from the linear range were determined in the SoftMax Pro software (Molecular Devices). All experiments were done with a sample volume of $100 \mu \mathrm{L}$. $\mathrm{IC}_{50}$ values were determined for all compounds in competition with $25 \mu \mathrm{M}$ of the chromogenic substrate nitrocefin. The $\log _{10}$ of the inhibitor concentrations to the response with bottom and top constant based on controls were fitted nonlinearly in GraphPad Prism 6 (GraphPad Software) to determine the $\mathrm{IC}_{50}$ value.

All SPR experiments were performed on a Biacore T200 at $25{ }^{\circ} \mathrm{C}$. The data were analyzed using Biacore T200 Evaluation Software 2.0 (GE Healthcare). The sensorgrams were double reference subtracted using a reference surface and blank injections. The final running buffer included $50 \mathrm{mM}$ HEPES pH 7.0, $50 \mathrm{mM} \mathrm{K}_{2} \mathrm{SO}_{4}, 0.5 \%$ Tween-20, $50 \mathrm{mM} \mathrm{NaHCO}$, and 2.5\% DMSO. The enzyme, tOXA-48, was diluted to $25 \mu \mathrm{g} / \mathrm{mL}$ in $10 \mathrm{mM}$ MES pH 5.5. The enzyme was immobilized to a level of around $5000 \mathrm{RU}$ on a CM5 chip using standard amine coupling.

Compounds were tested with 10 dilutions from $400 \mu \mathrm{M}$ to $10.5 \mu \mathrm{M}$, with 30 s injection and $60 \mathrm{~s}$ dissociation time. Compounds exhibiting kinetic behavior had the dissociation time extended to $300 \mathrm{~s}$. Seven startup cycles with buffer were performed. Solvent correction was performed every $48^{\text {th }}$ cycle and a positive control was included every $24^{\text {th }}$ cycle with 3.5-Di(4pyridinyl)benzoic acid as the control (19). Affinities were calculated from the steady-state affinity model with a constant $R_{\max }$ adjusted by the control and the molecular weight of the compound.

A solution of $\mathrm{NaH}^{13} \mathrm{CO} 3$ in $\mathrm{D}_{2} \mathrm{O}(50 \mathrm{mM})$ was prepared. The $\mathrm{NaH}^{13} \mathrm{CO}_{3} / \mathrm{D}_{2} \mathrm{O}$-mixture was added to $1 \mathrm{mM}$ OXA-48 in $50 \mathrm{mM}$ sodium phosphate and $50 \mathrm{mM}$ sodium bicarbonate $\mathrm{pH} 6.5$ in a $1: 9$ ratio of bicarbonate to enzyme. Compounds were diluted from a $150 \mathrm{mM}$ stock solution in $100 \%$ DMSO to a final concentration of $3.75 \mathrm{mM}$ (2.5\% DMSO). Sample volumes of $500 \mu \mathrm{L}$ were used. We performed the experiment at $37{ }^{\circ} \mathrm{C}$ with a Bruker Avance III HD with an inverse detected $\mathrm{TCl}$ probe with cryogenic enhancement for ${ }^{1} \mathrm{H},{ }^{13} \mathrm{C}$ and ${ }^{2} \mathrm{H}$, operating at $599.90 \mathrm{MHz}$ for protons and $150.86 \mathrm{MHz}$ for carbon. 10000 scans at $30^{\circ}$ pulse angle with $2 \mathrm{~s}$ relaxation delay were collected using $1 \mathrm{D}{ }^{13} \mathrm{C}$ NMR with power-gated decoupling of protons (zgpg30 using waltz16).

\section{$700 \quad 4.6 \quad$ Crystallization and data processing}


ethanediol, usually overnight. The exception was the crystal soaked in imipenem. Imipenem was added to saturation in the cryosolution, and the crystal was just given a quick soak.

Crystals were flash cooled in liquid nitrogen. X-ray diffraction data were collected at BL 14.1 and BL14.2 at BESSY (Berlin, Germany) (32) and at ID23 and ID30 at ESRF (Grenoble, France). In most cases the structures were solved by refining against the protein-atoms of previous structures (P212121 PDB ID: 5DVA and P21 PDB ID: 5DTK), but in cases where the unit cells were to different PHASER was used with chain A from PDB ID: $5 \mathrm{dtk}$ as the search model for molecular replacement. In most cases images were collected autoprocessed using the tools at the beamlines,(33-37) but in some cases we found it useful to reprocess using DIALS or XDS together with AIMLESS.(38-40)

The compounds were built into difference density maps after initial refinement in phenix.refine,(41) with waters deleted from the active site. Restraints for the compounds were prepared using the GRADE Web Server.(42) Omit maps were calculated using the phenix.polder-tool which excludes bulk-solvent from the volume surrounding the ligand.(43) Figures were made using PyMOL.(44) Ligand-interaction diagrams were prepared using the Maestro-suite from Schrödinger Release 2016-3 (Schrödinger, LLC, New York).

Acknowledgement:

This study was supported by The National Graduate School in Structural Biology (BioStruct) and The Norwegian Research Council (FRIMEDBIO project number 213808). Provision of beam time at BL14.1 and BL14.2, Bessy II, Berlin, Germany, and the MX beamlines at the European Radiation Facility (ESRF), Grenoble, France are highly valued.

PDB accession codes:

Coordinates and structure factors for all OXA-48 complexes are deposited in the Protein Data Bank. Accession numbers are listed with reference to the complexed compound. PDB IDs: imipenem: 5QB4; 3a: 5QA4; 3b: 5QA5; 4a: 5QA6; 4b: 5QA7; 4c: 5QA8; 5: 5QA9; 6a: 5QAA; 6b: 5QAB; 6c: 5QAC; 8a: 5QAD; 8b: 5QAE; 8c: 5QAF;9a: 5QAG; 9b: 5QAH; 12a: 5QAl: 13: 5QAJ; 14: 5QAK; 11b: 5QAL; 17: 5QAM; 19a: 5QAN; 19b: 5QAO; 21a: 5QAP; 21b: 5QAQ; 23a: 5QAR; 23b: 5QAS; 24: 5QAT; 26a: 5QAU; 26b: 5QAV; 27: 5QAW; 28: 5QAX; 32: 5QAY; 34: 5QAZ; 35: 5QB0; 36: 5QB1; 38: 5QB2; 40: 5QB3.

Supplementary material:

Supplementary material containing synthetic procedures and analytical data for all compounds and biophysical, biochemical and structural analysis of OXA-48:compound complexes.

\section{References:}

1. Guillard, T., Pons, S., Roux, D., Pier, G. B., and Skurnik, D. (2016) Antibiotic resistance and virulence: Understanding the link and its consequences for prophylaxis and therapy. Bioessays 38, 682-693 
2. Chen, L., Todd, R., Kiehlbauch, J., Walters, M., and Kallen, A. (2017) Notes from the Field: PanResistant New Delhi Metallo- $\beta$-Lactamase-Producing Klebsiella pneumoniae - Washoe County, Nevada, 2016. MMWR Morb. Mortal. Wkly. Rep. 66, 33-33

3. O'Neill, J. (2016) Tackling Drug-Resistant Infections Globally: final report and recommendations. Review on Antimicrobial Resistance, London, UK

4. Bush, K., and Bradford, P. A. (2016) $\beta$-Lactams and $\beta$-Lactamase Inhibitors: An Overview. CSH Perspect. Med. 6

5. Hall, B. G., and Barlow, M. (2004) Evolution of the serine $\beta$-lactamases: past, present and future. Drug Resist. Update. 7, 111-123

6. Poirel, L., Naas, T., and Nordmann, P. (2010) Diversity, Epidemiology, and Genetics of Class D $\beta$-Lactamases. Antimicrob. Agents Chemother. 54, 24-38

7. Bush, K., and Jacoby, G. A. (2010) Updated functional classification of $\beta$-lactamases. Antimicrob. Agents Chemother. 54, 969-976

8. Naas, T., Oueslati, S., Bonnin, R. A., Dabos, M. L., Zavala, A., Dortet, L., Retailleau, P., and lorga, B. I. (2017) Beta-lactamase database (BLDB) - structure and function. Journal of Enzyme Inhibition and Medicinal Chemistry 32, 917-919

9. Ambler, R. P. (1980) The structure of $\beta$-lactamases. Philos. Trans. R. Soc., B 289, 321-331

10. Golemi, D., Maveyraud, L., Vakulenko, S., Samama, J.-P., and Mobashery, S. (2001) Critical involvement of a carbamylated lysine in catalytic function of class D $\beta$-lactamases. Proc. Natl. Acad. Sci. U. S. A. 98, 14280-14285

11. Poirel, L., Potron, A., and Nordmann, P. (2012) OXA-48-like carbapenemases: the phantom menace. J. Antimicrob. Chemoth. 67, 1597-1606

12. Drawz, S. M., and Bonomo, R. a. (2010) Three decades of $\beta$-lactamase inhibitors. Clin. Microbiol. Rev. 23, 160-201

13. Buynak, J. D. (2006) Understanding the longevity of the $\beta$-lactam antibiotics and of antibiotic/ $\beta$-lactamase inhibitor combinations. Biochem. Pharmacol. 71, 930-940

14. Antunes, N., and Fisher, J. (2014) Acquired Class D $\beta$-Lactamases. Antibiotics 3, 398

15. Liscio, J. L., Mahoney, M. V., and Hirsch, E. B. (2015) Ceftolozane/tazobactam and ceftazidime/avibactam: two novel $\beta$-lactam/ $\beta$-lactamase inhibitor combination agents for the treatment of resistant Gram-negative bacterial infections. Int. J. Antimicrob. Agents 46, 266271

16. Ehmann, D. E., Jahić, H., Ross, P. L., Gu, R.-F., Hu, J., Durand-Réville, T. F., Lahiri, S., Thresher, J., Livchak, S., Gao, N., Palmer, T., Walkup, G. K., and Fisher, S. L. (2013) Kinetics of Avibactam Inhibition against Class A, C, and D $\beta$-Lactamases. J. Bio. Chem. 288, 27960-27971

17. Lahiri, S. D., Mangani, S., Jahic, H., Benvenuti, M., Durand-Reville, T. F., De Luca, F., Ehmann, D. E., Rossolini, G. M., Alm, R. A., and Docquier, J. D. (2015) Molecular Basis of Selective Inhibition and Slow Reversibility of Avibactam against Class D Carbapenemases: A StructureGuided Study of OXA-24 and OXA-48. ACS Chem. Biol. 10, 591-600

18. Shields, R. K., Chen, L., Cheng, S. J., Chavda, K. D., Press, E. G., Snyder, A., Pandey, R., Doi, Y., Kreiswirth, B. N., Nguyen, M. H., and Clancy, C. J. (2017) Emergence of CeftazidimeAvibactam Resistance Due to Plasmid-Borne bla(KPC-3) Mutations during Treatment of Carbapenem-Resistant Klebsiella pneumoniae Infections. Antimicrob. Agents Chemother. 61

19. Lund, B. A., Christopeit, T., Guttormsen, Y., Bayer, A., and Leiros, H. K. S. (2016) Screening and Design of Inhibitor Scaffolds for the Antibiotic Resistance Oxacillinase-48 (OXA-48) through Surface Plasmon Resonance Screening. J. Med. Chem. 59, 5542-5554

20. Congreve, M., Carr, R., Murray, C., and Jhoti, H. (2003) A 'Rule of Three' for fragment-based lead discovery? Drug Discov. Today 8, 876--877

21. Lukyanov, S. M., Bliznets, I. V., Shorshnev, S. V., Aleksandrov, G. G., Stepanov, A. E., and Vasil'ev, A. A. (2006) Microwave-assisted synthesis and transformations of sterically hindered 3-(5-tetrazolyl)pyridines. Tetrahedron 62, 1849-1863

22. King, A. M., King, D. T., French, S., Brouillette, E., Asli, A., Alexander, J. A. N., Vuckovic, M., Maiti, S. N., Parr, T. R., Brown, E. D., Malouin, F., Strynadka, N. C. J., and Wright, G. D. (2016) 
Structural and Kinetic Characterization of Diazabicyclooctanes as Dual Inhibitors of Both Serine- $\beta$-Lactamases and Penicillin-Binding Proteins. ACS Chem. Biol. 11, 864-868

23. Leonard, D. A., Bonomo, R. A., and Powers, R. A. (2013) Class D $\beta$-Lactamases: A Reappraisal after Five Decades. Acc. Chem. Res. 46, 2407-2415

24. Maveyraud, L., Golemi-Kotra, D., Ishiwata, A., Meroueh, O., Mobashery, S., and Samama, J.-P. (2002) High-Resolution X-ray Structure of an Acyl-Enzyme Species for the Class D OXA-10 $\beta$ Lactamase. J. Am. Chem. Soc. 124, 2461-2465

25. Cahill, S. T., Cain, R., Wang, D. Y., Lohans, C. T., Wareham, D. W., Oswin, H. P., Mohammed, J., Spencer, J., Fishwick, C. W. G., McDonough, M. A., Schofield, C. J., and Brem, J. (2017) Cyclic Boronates Inhibit All Classes of $\beta$-Lactamases. Antimicrob. Agents Chemother. 61

26. Li, J., Cross, J. B., Vreven, T., Meroueh, S. O., Mobashery, S., and Schlegel, H. B. (2005) Lysine carboxylation in proteins: OXA-10 $\beta$-lactamase. Proteins 61, 246-257

27. Verma, V., Testero, S. A., Amini, K., Wei, W., Liu, J., Balachandran, N., Monoharan, T., Stynes, S., Kotra, L. P., and Golemi-Kotra, D. (2011) Hydrolytic Mechanism of OXA-58 Enzyme, a Carbapenem-hydrolyzing Class D $\beta$-Lactamase from Acinetobacter baumannii. J. Bio. Chem. 286, 37292-37303

28. Lohans, C. T., Wang, D. Y., Jorgensen, C., Cahill, S. T., Clifton, I. J., McDonough, M. A., Oswin, H. P., Spencer, J., Domene, C., Claridge, T. D. W., Brem, J., and Schofield, C. J. (2017) ${ }^{13}$ CCarbamylation as a Mechanistic Probe for the Inhibition of Class D $\beta$-Lactamases by Avibactam and Halide lons. Org. Biomol. Chem. 15, 6024.

29. Asakawa, N., Kuroki, S., Kurosu, H., Ando, I., Shoji, A., and Ozaki, T. (1992) Hydrogen-bonding effect on carbon-13 NMR chemical shifts of L-alanine residue carbonyl carbons of peptides in the solid state. J. Am. Chem. Soc. 114, 3261-3265

30. Giannetti, A. M., Koch, B. D., and Browner, M. F. (2008) Surface plasmon resonance based assay for the detection and characterization of promiscuous inhibitors. J. Med. Chem. 51, 574-580

31. Lund, B. A., Leiros, H. K., and Bjerga, G. E. (2014) A high-throughput, restriction-free cloning and screening strategy based on $c c d B$-gene replacement. Microb. Cell Fact. 13, 38

32. Mueller, U., Förster, R., Hellmig, M., Huschmann, F. U., Kastner, A., Malecki, P., Pühringer, S., Röwer, M., Sparta, K., Steffien, M., Ühlein, M., Wilk, P., and Weiss, M. S. (2015) The macromolecular crystallography beamlines at BESSY II of the Helmholtz-Zentrum Berlin: Current status and perspectives. Eur. Phys. J. Plus 130, 141

33. Gabadinho, J., Beteva, A., Guijarro, M., Rey-Bakaikoa, V., Spruce, D., Bowler, M. W., Brockhauser, S., Flot, D., Gordon, E. J., Hall, D. R., Lavault, B., McCarthy, A. A., McCarthy, J., Mitchell, E., Monaco, S., Mueller-Dieckmann, C., Nurizzo, D., Ravelli, R. B. G., Thibault, X., Walsh, M. A., Leonard, G. A., and McSweeney, S. M. (2010) MxCuBE: a synchrotron beamline control environment customized for rnacromolecular crystallography experiments. J. Synchrotron. Radiat. 17, 700-707

34. Incardona, M. F., Bourenkov, G. P., Levik, K., Pieritz, R. A., Popov, A. N., and Svensson, O. (2009) EDNA: a framework for plugin-based applications applied to X-ray experiment online data analysis. J. Synchrotron. Radiat. 16, 872-879

35. Delageniere, S., Brenchereau, P., Launer, L., Ashton, A. W., Leal, R., Veyrier, S., Gabadinho, J., Gordon, E. J., Jones, S. D., Levik, K. E., McSweeney, S. M., Monaco, S., Nanao, M., Spruce, D., Svensson, O., Walsh, M. A., and Leonard, G. A. (2011) ISPyB: an information management system for synchrotron macromolecular crystallography. Bioinformatics 27, 3186-3192

36. Bourenkov, G. P., and Popov, A. N. (2010) Optimization of data collection taking radiation damage into account. Acta Cryst. Section D 66, 409-419

37. Sparta, K. M., Krug, M., Heinemann, U., Mueller, U., and Weiss, M. S. (2016) XDSAPP2. 0. J. Appl. Cryst. 49, 1085-1092

38. Waterman, D. G., Winter, G., Gildea, R. J., Parkhurst, J. M., Brewster, A. S., Sauter, N. K., and Evans, G. (2016) Diffraction-geometry refinement in the DIALS framework. Acta Cryst. Section D 72, 558-575 
39. Evans, P. R., and Murshudov, G. N. (2013) How good are my data and what is the resolution? Acta Cryst. Section D 69, 1204-1214

40. Kabsch, W. (2010) XDS. Acta Cryst. Section D 66, 125-132

41. Afonine, P. V., Grosse-Kunstleve, R. W., Echols, N., Headd, J. J., Moriarty, N. W., Mustyakimov, M., Terwilliger, T. C., Urzhumtsev, A., Zwart, P. H., and Adams, P. D. (2012) Towards automated crystallographic structure refinement with phenix.refine. Acta Cryst. Section D 68, 352-367

42. Smart, O. S., Womack, T. O., Sharff, A., Flensburg, C., Keller, P., Paciorek, W., Vonrhein, C., and Bricogne, G. (2014) grade, version 1.102. Global Phasing

43. Liebschner, D. (2016) phenix.polder - A tool for calculating difference maps around atom selections by excluding the bulk solvent mask. The Phenix Project, Berkeley, California 